\title{
Increased oxygen extraction and mitochondrial protein expression after small muscle mass endurance training
}

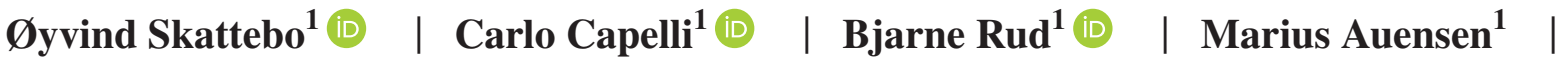 \\ Jose A. L. Calbet ${ }^{1,2,3}$ (id) | Jostein Hallén ${ }^{1}$ (ㄷ)
}

${ }^{1}$ Department of Physical Performance, Norwegian School of Sport Sciences, Oslo, Norway

${ }^{2}$ Department of Physical Education, University of Las Palmas de Gran Canaria, Spain

${ }^{3}$ Research Institute of Biomedical and Health Sciences (IUIBS), Las Palmas de Gran Canaria, Spain

\section{Correspondence}

Øyvind Skattebo, Norwegian School of Sport Sciences, Post box 4014 Ullevål Stadion, 0806 Oslo, Norway.

Email: oyvind.skattebo@nih.no

Present address

Carlo Capelli, Department of

Neurosciences, Biomedicine and Movement Sciences, University of Verona, Verona, Italy

\section{Funding information}

This study was funded by the Norwegian School of Sport Sciences and Ministerio de Economía y Competitividad (DEP201786409-C2-1-P).
When exercising with a small muscle mass, the mass-specific $\mathrm{O}_{2}$ delivery exceeds the muscle oxidative capacity resulting in a lower $\mathrm{O}_{2}$ extraction compared with wholebody exercise. We elevated the muscle oxidative capacity and tested its impact on $\mathrm{O}_{2}$ extraction during small muscle mass exercise. Nine individuals conducted six weeks of one-legged knee extension (1L-KE) endurance training. After training, the trained leg (TL) displayed 45\% higher citrate synthase and COX-IV protein content in vastus lateralis and $15 \%-22 \%$ higher pulmonary oxygen uptake $\left(\dot{\mathrm{V}}_{2 \text { peak }}\right)$ and peak power output $\left(\dot{\mathrm{W}}_{\text {peak }}\right)$ during $1 \mathrm{~L}-\mathrm{KE}$ than the control leg $(\mathrm{CON}$; all $P<.05)$. Leg $\mathrm{O}_{2}$ extraction (catheters) and blood flow (ultrasound Doppler) were measured while both legs exercised simultaneously during $2 \mathrm{~L}-\mathrm{KE}$ at the same submaximal power outputs (real-time feedback-controlled). TL displayed higher $\mathrm{O}_{2}$ extraction than CON (main effect: $1.7 \pm 1.6 \%$ points; $P=.010 ; 40 \%-83 \%$ of $\left.\dot{\mathrm{W}}_{\text {peak }}\right)$ with the largest between-leg difference at $83 \%$ of $\dot{\mathrm{W}}_{\text {peak }}\left(\mathrm{O}_{2}\right.$ extraction: $3.2 \pm 2.2 \%$ points; arteriovenous $\mathrm{O}_{2}$ difference: $\left.7.1 \pm 4.8 \mathrm{~mL} \cdot \mathrm{L}^{-1} ; P<.001\right)$. At $83 \%$ of $\dot{\mathrm{W}}_{\text {peak }}$, muscle $\mathrm{O}_{2}$ conductance $\left(\mathrm{D}_{\mathrm{M}} \mathrm{O}_{2}\right.$; Fick law of diffusion) and the equilibration index $\mathrm{Y}$ were higher in TL $(P<.01)$, indicating reduced diffusion limitations. The between-leg difference in $\mathrm{O}_{2}$ extraction correlated with the between-leg ratio of citrate synthase and COX-IV ( $r=.72-.73$; $P=.03)$, but not with the difference in the capillary-to-fiber ratio $(P=.965)$. In conclusion, endurance training improves $\mathrm{O}_{2}$ extraction during small muscle mass exercise by elevating the muscle oxidative capacity and the recruitment of $\mathrm{D}_{\mathrm{M}} \mathrm{O}_{2}$, especially evident during high-intensity exercise exploiting a larger fraction of the muscle oxidative capacity.

\section{K E Y W O R D S}

arteriovenous oxygen difference, blood flow, endurance training, fick method, limitations, maximal oxygen uptake, muscle oxygen diffusion, peripheral adaptations

\section{1 | INTRODUCTION}

During dynamic exercise involving a large muscle mass (>15 kg; ie, in cycling or running), maximal oxygen uptake $\left(\mathrm{V}_{2 \max }\right)$ is primarily limited by $\mathrm{O}_{2}$ delivery to the recruited 
limit muscle $\dot{\mathrm{VO}}_{2}$ per se..$^{2-4}$ Therefore, a more than twofold larger $\mathrm{O}_{2}$ delivery per unit muscle mass is observed during $1 \mathrm{~L}-\mathrm{KE}$ compared with cycling (500 vs $240 \mathrm{~mL} \cdot \mathrm{min}^{-1} \cdot \mathrm{k}-$ $\mathrm{g}^{-1}$ muscle, respectively). ${ }^{5}$ Despite this, the mass-specific $\mathrm{V}_{2}$ is only $\sim 70 \%$ higher due to a substantially lower leg $\mathrm{O}_{2}$ extraction during $1 \mathrm{~L}-\mathrm{KE} .{ }^{5}$

The decreased $\mathrm{O}_{2}$ extraction may be caused by fully activated mitochondria respiring near their maximal rate, ${ }^{5,6}$ a condition that may restrict further $\mathrm{O}_{2}$ extraction and $\mathrm{O}_{2}$ diffusion from the blood to cytochrome-c-oxidase. This is substantiated by a close to 1:1 relationship between the maximal activity of the Krebs cycle enzyme oxoglutarate dehydrogenase and the maximal flux rate within the Krebs cycle during 1L-KE. ${ }^{7}$ Consequently, leg $\mathrm{VO}_{2}$ is not enhanced by breathing hyperoxic gas during maximal $1 \mathrm{~L}-\mathrm{KE}$ exercise,${ }^{8-11}$ although this effect may depend on the training status. ${ }^{12}$ The higher mass-specific leg blood flow (LBF) and lower $\mathrm{O}_{2}$ extraction indicate that the $\dot{\mathrm{VO}}_{2}$ is more diffusion-limited than perfusion-limited, in contrast to the situation when exercising with a large muscle mass. ${ }^{5}$ Accordingly, when exercising with a small muscle mass, lower $\mathrm{O}_{2}$ extraction is expected if muscle oxidative capacity and $\mathrm{O}_{2}$ conductance $\left(\mathrm{D}_{\mathrm{M}} \mathrm{O}_{2}\right.$; the $\mathrm{V}_{2}$ divided by the $\mathrm{O}_{2}$ pressure gradient between the muscle capillaries and the mitochondria) are lowered, and vice versa. Indeed, leg immobilization decreases the muscle oxidative capacity resulting in impaired leg $\mathrm{O}_{2}$ extraction during $1 \mathrm{~L}-$ KE. ${ }^{13}$ Furthermore, during arm cycling, engaging a small muscle mass $(\sim 6 \mathrm{~kg})$ characterized by a substantially lower maximal mitochondrial respiratory capacity (OXPHOS; measured in permeabilized muscle fibers ex vivo) than its maximal $\mathrm{O}_{2}$ delivery, ${ }_{1}^{14}$ endurance training has proven to enhance $\mathrm{O}_{2}$ extraction. ${ }^{15}$ Although there is some controversy whether $\mathrm{O}_{2}$ extraction improves after endurance training during exercise with a large muscle mass, ${ }^{16-19}$ these data, in conjunction with animal data, ${ }^{20}$ suggest that the potential for improvement is greater during exercise with a small muscle mass.

When conducting whole-body endurance training (eg, cycling and running), both central and peripheral adaptations occur. ${ }^{19}$ Therefore, as $\mathrm{O}_{2}$ delivery and $\mathrm{O}_{2}$ extraction are interdependent, evaluation of the isolated effect of enhanced muscle oxidative capacity has proven to be difficult in humans. One way of avoiding this problem is to increase the oxidative capacity in only one leg by using one-legged endurance training. Subsequently, the trained leg and the contralateral control leg within the same subject can exercise simultaneously at the same power output. ${ }^{17}$ This experimental setup ensures equal perfusion pressure and arterial $\mathrm{O}_{2}$ content for both legs, meaning that (a) the $\mathrm{O}_{2}$ delivery should be similar and (b) every improvement in $\mathrm{O}_{2}$ extraction should originate from the changes in muscle oxidative capacity and/or capillarization. Similar experiments involving simultaneous exercise with one trained leg and one untrained leg have been conducted in the past. ${ }^{17,21,22}$ However, in two of these studies, care was not taken to balance the power output between the trained leg and the untrained leg (the trained leg performed more work), ${ }^{21,22}$ and all three studies used two-legged cycling where the muscles possess a large oxidative reserve capacity, even before training. ${ }^{14}$ In the study balancing the power output between legs, it was found a 3.5\% points higher $\mathrm{O}_{2}$ extraction in the trained leg at the highest power output (91\% of cycling $\dot{\mathrm{V}}_{2 \max }$ ), but no significant difference at low-to-moderate power outputs. ${ }^{17}$ During exercise with small muscle mass (ie, knee extension) involving a trained leg and an untrained leg, it is conceivable that a between-leg difference in $\mathrm{O}_{2}$ extraction may be more prominent since the mitochondria are respiring closer to their maximal rate and the $\mathrm{O}_{2}$ extraction is lower than during cycling 5,6 - that is, the muscle oxidative capacity may be more limiting in the untrained leg.

Based on the above premises, we aimed to increase the muscle oxidative capacity and test its impact on $\mathrm{O}_{2}$ extraction during exercise involving a small muscle mass. After six weeks of 1L-KE endurance training, the trained leg (TL) and the control leg (CON) were exercised simultaneously at the same absolute power output during $2 \mathrm{~L}-\mathrm{KE}$, a model engaging only $\sim 5 \mathrm{~kg}$ active skeletal muscle mass that minimizes the perfusion limitations as it does not tax $\dot{\mathrm{Q}}_{\max } \cdot{ }^{3}$ During three low- to high-intensity workloads, equaling $40 \pm 3 \%$, $62 \pm 4 \%$, and $83 \pm 4 \%$ of $2 \mathrm{~L}-\mathrm{KE}$ peak power output ( $\dot{\mathrm{W}}_{\text {peak }}$ ), leg $\mathrm{O}_{2}$ extraction (femoral arterial and venous catheters) and LBF (ultrasound Doppler) were measured for each leg. Muscle biopsies were taken from both legs before and after the training period and were analyzed for mitochondrial enzymes and capillarization. We hypothesized that leg $\mathrm{O}_{2}$ extraction would be higher in TL than in CON due to increased oxidative capacity and larger recruitment of $\mathrm{D}_{\mathrm{M}} \mathrm{O}_{2}$ after training. Moreover, as the oxidative capacity would be gradually more exploited by increasing exercise intensity, we hypothesized that a between-leg difference in $\mathrm{O}_{2}$ extraction would be more evident at high compared with low power outputs.

\section{2 | MATERIALS AND METHODS}

\subsection{Subjects and ethical approval}

Nine moderately trained subjects (age: $27.5 \pm 5.2$ years; height: $1.79 \pm 0.07 \mathrm{~m}$; weight: $79.0 \pm 10.6 \mathrm{~kg}$; lean body mass: $59.1 \pm 4.9 \mathrm{~kg} ; \dot{\mathrm{V}}{ }_{2 \max }: 55.5 \pm 9.5 \mathrm{~mL} \cdot \mathrm{kg}^{-1} \cdot \mathrm{min}^{-1}$ ) were recruited for study participation. The study was approved by the Ethics Committee of the Norwegian School of Sport Sciences (03-020517) and the Norwegian Centre for Research Data (53 552). Before study initiation, oral and written informed consents were obtained from all participants, and the study was conducted according to the Declaration of Helsinki. 


\section{2 | Experimental design}

After six weeks of 1L-KE endurance training, the participants performed $2 \mathrm{~L}-\mathrm{KE}$ exercise at three different power outputs: $40 \pm 3 \%, 62 \pm 4 \%$, and $83 \pm 4 \%$ of $2 \mathrm{~L}-\mathrm{KE} \dot{\mathrm{W}}_{\text {peak }}$ . Submaximal and near-maximal power outputs were chosen to ensure identical absolute power output produced by $\mathrm{TL}$ and the non-trained CON, although having a substantial difference in their training status and $\dot{\mathrm{W}}_{\text {peak }}$ during $1 \mathrm{~L}-\mathrm{KE}$. This was ensured using a real-time feedback system displaying the balance in power output produced by the two legs. LBF was measured, and blood samples were drawn simultaneously from catheters indwelling the femoral veins of both legs and from a femoral artery to measure leg $\mathrm{O}_{2}$ extraction and to calculate leg $\mathrm{V}_{2}$ and $\mathrm{D}_{\mathrm{M}} \mathrm{O}_{2}$ (main experiment).

Before and after the training intervention, measurements of pulmonary $\dot{\mathrm{V}}_{2 \text { max }}$ during cycling and pulmonary peak $\dot{\mathrm{VO}}_{2}\left(\dot{\mathrm{VO}}_{2 \text { peak }}\right)$ during $1 \mathrm{~L}-\mathrm{KE}$ (both legs) and $2 \mathrm{~L}-\mathrm{KE}$ were conducted. Body composition was measured after overnight fasting (dual-energy X-ray absorptiometry; Lunar iDXA; GE Healthcare), a muscle biopsy from each thigh was sampled, and the quadriceps femoris muscle mass was estimated anthropometrically ${ }^{23}$ and adjusted as proposed by Radegran. ${ }^{24}$

Before testing, several short familiarization sessions were conducted to ensure optimal technique during $1 \mathrm{~L}-\mathrm{KE}$ and $2 \mathrm{~L}-\mathrm{KE}$. The subjects were asked to refrain from physical activity the day before testing and sampling of muscle biopsies.

\subsection{Exercise training}

The subjects conducted supervised 1L-KE training 3-4 times per week over six weeks (21 sessions, $100 \%$ adherence). Training legs were counterbalanced between right and left legs among subjects. One session consisted of continuous exercise at $70 \%$ of $\dot{\mathrm{W}}_{\text {peak }}$ and progressed from 35 to $65 \mathrm{~min}$ utes during the training period. Another session consisted of 10-min warm-up, 20 minutes "all-out" at the highest possible power output, and a cooldown of 5 minutes. The third session consisted of a 10-min warm-up, and 4-6 repetitions of 5 minutes at $85 \%$ of $\dot{\mathrm{W}}_{\text {peak }}$, which were interspersed with recovery periods of 2 minutes and followed by a 5 -min cooldown. From weeks 1 to 6 , the total work performed increased from $197 \pm 23$ to $493 \pm 54 \mathrm{~kJ}$ per week. The subjects were asked to maintain their regular training in addition to the supervised 1L-KE training, which was $2.9 \pm 2.4$ hours of endurance training and $1.0 \pm 0.7$ hours of strength training per week during the intervention period. Each subject recorded their training by reporting the training mode, duration, and intensity in a custom-made Excel spreadsheet provided by the investigators.

\subsection{Non-invasive physical tests}

Pulmonary $\dot{\mathrm{V}}_{2 \max }$ was measured during cycling (Excalibur Sport; Lode BV, Groningen, The Netherlands) with step increments of $25 \mathrm{~W} \cdot \mathrm{min}^{-1}$ after 15 -minutes warm-up. On a separate day, pulmonary $\dot{\mathrm{V}}_{2 \text { peak }}$ and $\dot{\mathrm{W}}_{\text {peak }}$ were measured during $1 \mathrm{~L}-\mathrm{KE}$ (both legs, counterbalanced order) and 2LKE. Rest periods between legs and exercise modes were 15 and 45 minutes, respectively. The incremental tests began at $30 \mathrm{~W}$ or $60 \mathrm{~W}$, after a 15 -minutes warm-up, and were followed by step increments of $5 \mathrm{~W} \cdot \mathrm{min}^{-1}$ or $10 \mathrm{~W} \cdot \mathrm{min}^{-1}$ during 1L-KE and 2L-KE, respectively.

\section{5 | Catheterization and preparation for the main experiment}

The subjects reported to the laboratory at 8:00 or 14:00, and catheters were placed percutaneously under local anesthesia (2\% lidocaine) using the Seldinger technique. Briefly, a 20gauge catheter (Arrow ref. \# ES-04150; Teleflex Medical) was placed into the right femoral artery, $2-5 \mathrm{~cm}$ below the inguinal ligament and advanced $8 \mathrm{~cm}$ in the proximal direction. Another two 20-gauge catheters were placed in the femoral veins, $2 \mathrm{~cm}$ below the inguinal ligament and advanced $8 \mathrm{~cm}$ in the proximal direction. Catheter tip placement was confirmed using ultrasound B mode, and all catheters were sutured to the skin. The catheters were used for arterial and venous blood sampling and were connected to blood pressure transducers (TruWave ref. \# T450217A; Edward Lifesciences) positioned at the height of the parasternal fourth intercostal space. Via an amplifier (Gould Instrument Systems), blood pressures were sampled at $100 \mathrm{~Hz}$ using a PC with LabVIEW software (National Instruments).

\section{6 | Blood sampling and analytic procedures}

Blood was sampled anaerobically using heparinized syringes (safePICO; Radiometer) and immediately analyzed for hemoglobin concentration ([Hb]), hemoglobin $\mathrm{O}_{2}$ saturation $\left(\mathrm{SO}_{2}\right)$, the tension of $\mathrm{O}_{2}\left(\mathrm{PO}_{2}\right)$ and $\mathrm{CO}_{2}\left(\mathrm{PCO}_{2}\right), \mathrm{pH}$, and lactate using an ABL90 FLEX (Radiometer). Blood $\mathrm{O}_{2}$ content $\left(\mathrm{ctO}_{2}\right)$ was calculated as follows: $(1.34 \times[\mathrm{Hb}] \times \mathrm{S}$ $\left.\mathrm{O}_{2}\right)+\left(0.003 \times \mathrm{PO}_{2}\right)$. The in vivo $\mathrm{P}_{50} \mathrm{O}_{2}$ (the $\mathrm{PO}_{2}$ at $50 \%$ $\mathrm{SO}_{2}$ of $\mathrm{Hb}$ ) was calculated from blood gas measurements 
correcting for $\mathrm{PCO}_{2}$ and $\mathrm{pH}$ according to Kelman. ${ }^{25}$ Blood samples were taken simultaneously from both veins and the artery.

\section{7 | Femoral arterial blood flow}

LBF was measured in the femoral artery of both legs using ultrasound Doppler (Vivid E95; GE Vingmed Ultrasound AS) equipped with a linear transducer (9L-D; GE Vingmed Ultrasound AS) operating with an image frequency of $10 \mathrm{MHz}$ and a Doppler frequency of 3.7-4.0 MHz. Blood velocity was measured in the common femoral artery distal to the inguinal ligament, but above the bifurcation into the superficial and profound femoral branches to avoid turbulence. The sample volume was maximized according to the vessel width but kept clear of the vessel walls. The insonation angle was minimized and always below $60^{\circ}$. A low-velocity filter was applied to reject noise created from turbulence at the vessel wall. The arterial diameter was determined during systole (mean of three heart cycles) on each exercise bout from B-mode images with the transducer parallel to the vascular walls. For all subjects, measurements were first conducted on the left leg, followed by the right leg: B-mode left, Doppler left, Doppler right, and B-mode right. Blood velocity was measured continuously and averaged over $\sim 45$ seconds. LBF was measured $\sim 1.0-1.5 \mathrm{~min}$ earlier in the left leg compared with the right leg, but with no difference between the mean of TL and CON due to counterbalancing (see "Exercise protocol and timing of measurements" for more details). Recordings were anonymized before LBF was analyzed using software incorporated in the Vivid E95.

\section{8 | Calculations}

Arteriovenous $\mathrm{O}_{2}$ difference (a- $\mathrm{vO}_{2}$ diff) was computed as the difference between femoral arterial and femoral venous $\mathrm{ctO}_{2}$ for each leg. The a- $\mathrm{vO}_{2}$ diff divided by the arterial $\mathrm{ctO}_{2}$ gave $\mathrm{O}_{2}$ extraction. Leg $\mathrm{O}_{2}$ delivery was calculated as the product of $\mathrm{LBF}$ and arterial $\mathrm{ctO}_{2}$. $\mathrm{Leg} \dot{\mathrm{VO}}_{2}$ was the product of $\mathrm{LBF}$ and a- $\mathrm{VO}_{2}$ diff. Leg vascular conductance was calculated as LBF divided by the mean arterial pressure minus femoral venous pressure. Mean capillary $\mathrm{PO}_{2}$ and the muscle $\mathrm{O}_{2}$ conductance $\left(\mathrm{D}_{\mathrm{M}} \mathrm{O}_{2}\right)$ were calculated as previously described, ${ }^{26,27}$ using the measured arterial and femoral venous $\mathrm{PO}_{2} . \mathrm{D}_{\mathrm{M}} \mathrm{O}_{2}\left[\mathrm{~V}_{2} /\right.$ (mean capillary $\mathrm{PO}_{2}-$ mitochondrial $\mathrm{PO}_{2}$ )] is recognized as a compound variable integrating several steps in the $\mathrm{O}_{2}$ cascade, including the chemical dissociation of $\mathrm{O}_{2}$ from $\mathrm{Hb}$, and diffusion through the erythrocyte membrane, plasma, capillary wall, interstitial space, sarcolemma, cytoplasm (myoglobin-facilitated or by diffusion), and into the mitochondria for utilization by the cytochromes. The calculated $\mathrm{D}_{\mathrm{M}} \mathrm{O}_{2}$ depends on the recruited exercise muscle mass, ${ }^{5} \mathrm{~F}_{\mathrm{I}} \mathrm{O}_{2}$, and exercise intensity. ${ }^{2,28}$ Since the observed $\mathrm{D}_{\mathrm{M}} \mathrm{O}_{2}$ is higher during cycling than $1 \mathrm{~L}-\mathrm{KE}$ (reversed if standardizing to the active muscle mass), ${ }^{5,12}$ and also higher in hypoxia than normoxia; ${ }^{2,28}$ we describe potential between-leg differences in $\mathrm{D}_{\mathrm{M}} \mathrm{O}_{2}$ as differences in the "recruitment" of $\mathrm{D}_{\mathrm{M}} \mathrm{O}_{2}$ rather than a difference in the maximal capacity. ${ }^{28}$ The equilibration index $\mathrm{Y}\left[\mathrm{D}_{\mathrm{M}} \mathrm{O}_{2} /\right.$ (LBF. $\beta$ )], which quantitatively describes perfusion vs diffusion limitations to $\dot{\mathrm{VO}}_{2}$, was calculated according to Piiper and Scheid. ${ }^{29}$ In this calculation, $\beta$ is the mean slope of the $\mathrm{O}_{2}-\mathrm{Hb}$ dissociation curve (ODC) and was calculated as $\mathrm{V}_{2} /$ $\left[\mathrm{LBF} \cdot\left(\right.\right.$ arterial $\mathrm{PO}_{2}-$ femoral venous $\left.\left.\mathrm{PO}_{2}\right)\right]{ }^{29}$

\section{9 | Pulmonary gas exchange}

Pulmonary $\mathrm{V}_{2}$ was measured using a metabolic cart with a mixing chamber (Oxycon Pro; Jaeger Instrument). Before each test, the gas analyzers and flow transducer (Triple V; Erich Jaeger $\mathrm{GmbH}$ ) were calibrated according to the instruction manual.

\subsection{0 | Knee extension ergometer}

Knee extension exercises were performed on an electromagnetically braked ergometer modified after Hallén. ${ }^{30}$ Briefly, the ergometer isolates leg muscle contractions to quadriceps femoris during knee extensions. ${ }^{31}$ The hip angle was $\sim 128^{\circ}$, and the upper body was strapped using a four-point seat belt to minimize the engagement of muscle mass to stabilize the body. By adding a steel bar to the pedal arm on either one or both sides of the flywheel, both $1 \mathrm{~L}-\mathrm{KE}$ and $2 \mathrm{~L}-\mathrm{KE}$ could be conducted. The steel bars have an integrated telescope function and are shortened if the subject tries to produce any force on the flywheel in the recovery/knee-flexion phase, guaranteeing no hamstring contribution to the power output. Strain gauges were incorporated in the steel bars, and the angles of the pedal arms were continuously monitored. The work performed on the flywheel was calculated and recorded by custom-made software. During 2L-KE, the work expressed as the balance between the legs was displayed in real time on a monitor in front of the subjects to ensure equal involvement of both legs. In addition, the kicking frequency was displayed on the same monitor and was maintained at $60 \mathrm{rpm}$.

\subsection{1 | Exercise protocol and timing of measurements (main experiment)}

First, a baseline measurement was conducted after 10-minutes rest seated in the KE ergometer. Thereafter, three 8-minutes exercise bouts at low $(47 \pm 7 \mathrm{~W}$; ie, $23.5 \mathrm{~W}$ by each 


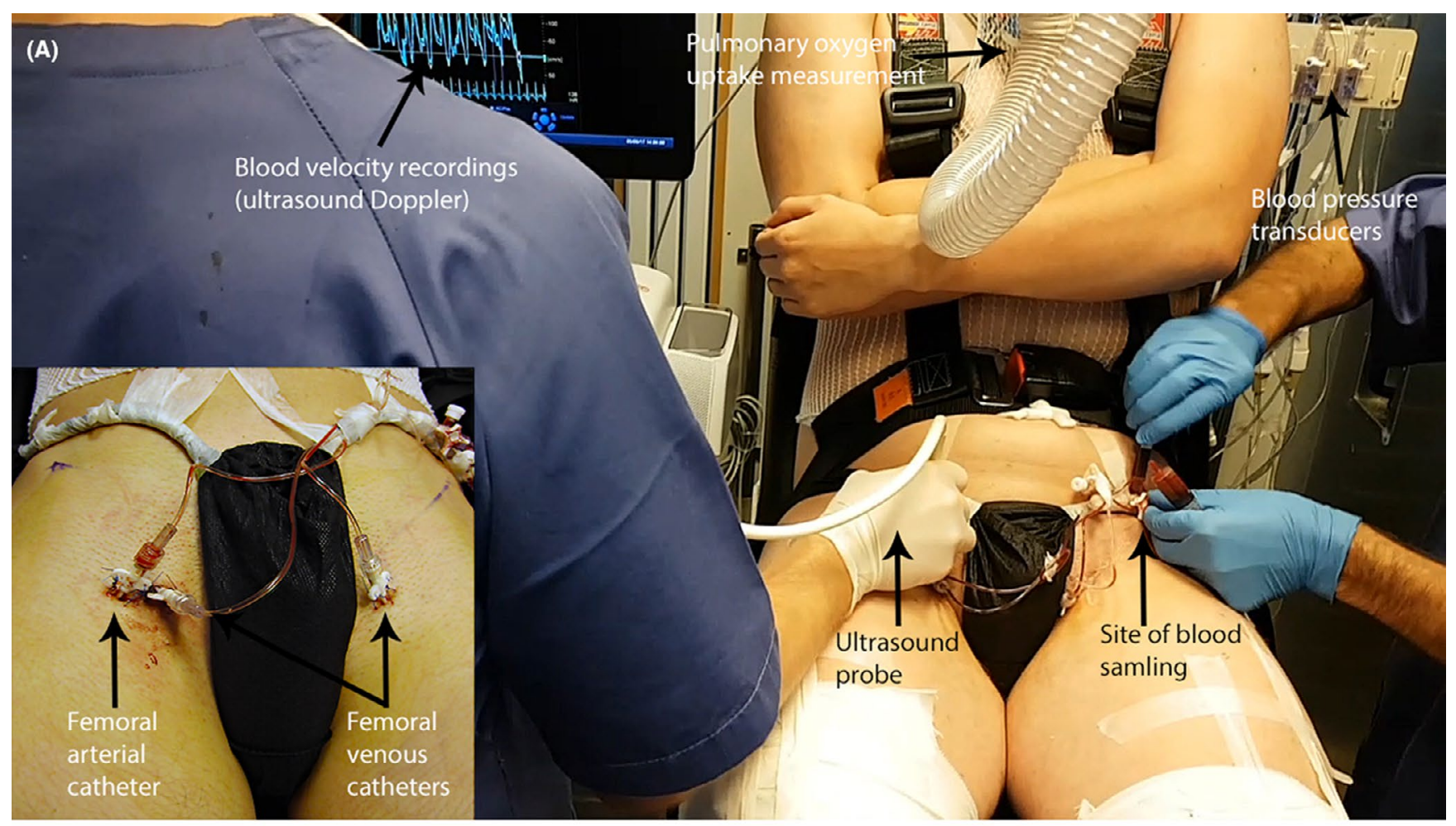

(B)

"High intensity"

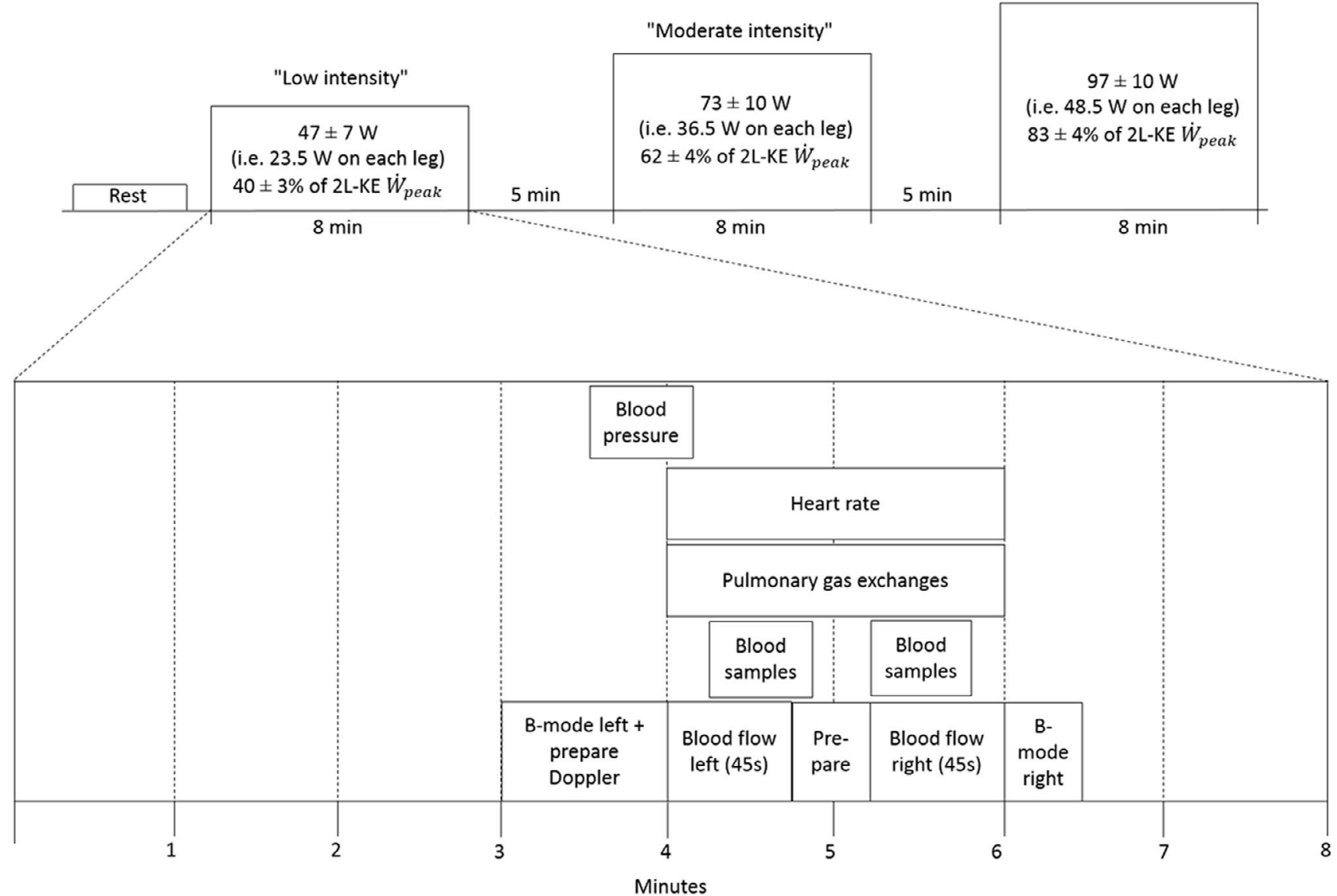

F I G U R E 1 The full setup of a subject seated in the knee extension ergometer (A); and the exercise protocol and timing of measurements (B). These measurements were conducted after training only 
leg), moderate (73 $\pm 10 \mathrm{~W}$; ie, $36.5 \mathrm{~W}$ by each leg), and high $(97 \pm 10 \mathrm{~W}$; ie, $48.5 \mathrm{~W}$ by each leg) intensity $(40 \pm 3 \%$, $62 \pm 4 \%$ and $83 \pm 4 \%$ of $2 \mathrm{~L}-\mathrm{KE} \dot{\mathrm{W}}_{\text {peak }}$, respectively) were conducted, interspersed by 5 -min passive rest periods (see Figure 1 for the full setup of a subject and the design and timing of measurements). Post-hoc analysis showed equal involvement of both legs during experiments (TL accounted for $50.3 \pm 0.8 \%, 50.6 \pm 0.8 \%$, and $50.8 \pm 1.3 \%$ of the power output at low, moderate, and high intensity, respectively). During each bout, the subjects used the first 1-2 minute(s) to fine-tune equal involvements of legs and to reach "steady state." After 3 minutes, B-mode imaging of the left femoral artery began, followed by Doppler measurements from precisely 4 minutes on the left leg and approximately from 5 minutes on the right leg. Two blood samples from each vessel were drawn during the Doppler measurements ( 4.5 and $\sim 5.5$ minutes), and the duplicates were averaged. Blood pressures were calculated as $\sim 30$-seconds averages preceding the first blood sample. Heart rate was averaged from ECGs during Doppler measurements. At the end of each exercise bout, the subjects were asked to rate the perceived intensity for each leg separately using the CR-10 scale. ${ }^{32}$ Exercising at low intensity elicited equal perceived intensity $(2.3 \pm 1.0 \mathrm{vs}$ $2.3 \pm 1.5 ; P=1.00)$, while moderate $(4.6 \pm 1.8$ vs $3.8 \pm 2.1$; $P=.008)$ and high $(8.6 \pm 1.7$ vs $6.9 \pm 2.3 ; P<.001)$ intensity exercise elicited significantly higher perceived intensity in CON than in TL.

\subsection{2 | Skeletal muscle biopsy}

Muscle biopsies ( 100-200 mg) were collected from the mid-portion of vastus lateralis after local anesthesia, using the Bergström technique with manual suction. The tissue was immediately dissected free from visible fat and connective tissue. An appropriate sample for immunohistochemistry was embedded in OCT embedding matrix (CellPath) and quickly frozen in isopentane cooled on liquid nitrogen to freezing point (approx. $-120^{\circ} \mathrm{C}$ ). Tissue allocated for Western blotting was immediately snap-frozen in liquid nitrogen. All tissue samples were stored at $-80^{\circ} \mathrm{C}$ until further analysis.

\subsection{3 | Immunohistochemistry}

Serial 8- $\mu \mathrm{m}$ transverse cross sections were cut at $-20^{\circ} \mathrm{C}$ (Leica CM1860 UV; Leica Biosystems), mounted on microscope slides (Superfrost Plus; Thermo Fisher Scientific), air-dried, and stored at $-80^{\circ} \mathrm{C}$ until further analysis. The sections were blocked for $60 \mathrm{~min}$ with $10 \%$ goat serum (ab7481; Abcam) and 1\% bovine serum albumin (Sigma Life Science) in a phosphate-buffered saline (Sigma Life Science) and $0.05 \%$ Tween-20 (VWR) solution (PBS-t). Primary antibodies against (a) myosin heavy-chain type 1 (1:500 dilution; BA-D5, developed by Schiaffino, S., obtained from DSHB) and dystrophin (1:500; ab15277; Abcam), or (b) the endothelial marker CD31 (1:100; M0823; Dako A/S) and dystrophin were diluted in the blocking solution and incubated overnight at $4^{\circ} \mathrm{C}$. The sections were then washed $3 \times 10$ minutes in PBS-t, incubated with secondary antibodies (1:200; Alexa Fluor 488, A1 1001 and A11012; Invitrogen Molecular Probes) for 60 minutes, and again washed $3 \times 10$ minutes in PBS-t before being mounted with Prolong Gold Antifade Reagent with DAPI (Life Technologies Corp.) and covered with a cover glass. The sections were visualized under a $10 \times / 0.30 \mathrm{NA}$ air objective (UplanFL N; Olympus corp.) and micrographed using a high-resolution digital camera (DP72; Olympus corp.) attached to a microscope (BX61; Olympus corp.) with a fluorescence light source (X-Cite 120 PC Q; EXFO Photonic Solution Inc). Fiber cross-sectional areas, fiber types, and manual identification of capillaries were conducted and analyzed using TEMA software (CheckVision). The investigator was blinded for the subject and leg identity. A mean of $189 \pm 41$ (range: 118-251) fibers was analyzed. Capillarization was expressed as the capillary-to-fiber ratio, capillaries in contact with each fiber, and capillary density (capillaries per $\mathrm{mm}^{2}$ ).

\subsection{4 | Protein immunoblot}

For Western blotting analyses, $\sim 60 \mathrm{mg}$ of muscle tissue was homogenized in $1 \mathrm{~mL}$ T-PER (Tissue Protein Extraction Reagent, 78 510; Thermo Fisher Scientific) and $20 \mu \mathrm{L}$ Halt Protease and Phosphatase Inhibitor Cocktail (78 440; Thermo Fisher Scientific). The tissue lysate was extracted, aliquoted, and stored at $-80^{\circ} \mathrm{C}$ until further analyses. The protein concentration was measured using a commercial kit (BioRad DC Protein Assay, 5000 116; Bio-Rad Laboratories) and a FLUOstar Omega microplate reader (BMG Labtech). Standard Western blotting procedures were applied for quantification of citrate synthase, cytochrome-c-oxidase subunit 4 (COX-IV), and hydroxyacyl-CoA dehydrogenase (HAD) as surrogates indices of mitochondrial volume density. ${ }^{33}$ $20 \mu \mathrm{g}$ of protein was separated by $4 \%-12 \%$ gradient Bis-Tris gels (Invitrogen, Life Technologies) for $\sim 45 \mathrm{~min}$ at 200 volts in cold buffer (NuPage MES SDS Running Buffer; Invitrogen, Life Technologies). Proteins were subsequently transferred onto a PVDF membrane (Bio-Rad Laboratories) at 30 volts for $90 \mathrm{~min}$ in cold buffer (NuPage Transfer Buffer; Invitrogen, Life Technologies). Membranes were blocked at room temperature for 2 hours in a $5 \%$ fat-free skimmed milk (Merck) and 0.1\% TBS-t solution (TBS: BioRad Laboratories; Tween-20: VWR). Thereafter, the membranes were divided into pieces based on molecular weight (Protein Ladder 310 005; GeneON) and then incubated 
overnight $\left(4^{\circ} \mathrm{C}\right)$ with primary antibodies against citrate synthase (1:4000; ab96600; Abcam), COX-IV (1:2000; ab16056; Abcam), or HAD (1:8000; ab154088; Abcam). An anti-rabbit IgG (1:3000; 7074S; Cell Signaling Technology) secondary antibody was applied for 1 hour at room temperature followed by visualization using an HRP detection system (Super Signal West Dura Extended Duration Substrate; Thermo Fisher Scientific). An antibody against the loading control GAPDH (1:3000; ab9484; Abcam) was applied as a secondary probe after using Restore Western Blot Stripping Buffer (21 059; Thermo Fisher Scientific). All antibodies were diluted in a $1 \%$ fat-free skimmed milk and $0.1 \%$ TBS-t solution. Between steps, membranes were washed in $0.1 \%$ TBS-t and TBS solutions. Chemiluminescence was detected using the ChemiDoc MP system with band intensities quantified using Image Lab 5.1 software (Bio-Rad Laboratories). Pre-samples and post-samples of both legs were loaded on the same gel in duplicates using a counterbalanced order, and mean values were used for statistical analysis. In addition, a human control sample (a pool of all biopsies in the present project) was loaded in duplicate on each gel, and the average intensity of this sample was used for normalization to allow for semi-quantitative comparisons across gels/subjects. ${ }^{34}$

\subsection{Statistical analyses}

Data in text and tables are presented as mean \pm standard deviation (SD) and in graphs as mean \pm standard error of the mean (SEM) if not otherwise stated. The data were initially assessed for normal distribution using the D'AgostinoPearson test. Differences between legs during exercise and differences in protein content between pre-training and posttraining were analyzed using two-way repeated-measures ANOVA (leg $\times$ power output and leg $\times$ time point, respectively). If a significant main effect or interaction effect was found, the ANOVA was followed by Bonferroni's multiple comparison post-hoc test. Differences between legs during rest and one-level changes from pre- to post-training were analyzed with a paired sample $t$ test. The alpha level was set to $<0.05$, and values between $\geq 0.05$ and $\leq 0.10$ were considered to indicate trends. GraphPad Prism (v. 8.0.1; GraphPad Software) and Microsoft Office Excel 2013 (Microsoft Corporation) were used for statistical analysis.

\section{3 | RESULTS}

\section{1 | Pulmonary gas exchange and muscle mass}

Post-training, $\dot{\mathrm{W}}_{\text {peak }}$ during $1 \mathrm{~L}-\mathrm{KE}$ was $15 \pm 8 \%$ higher during incremental exercise to exhaustion with TL compared to $\mathrm{CON}(P<.001$; Table 1$)$. This was accompanied by $20 \pm 11 \%$ longer time to exhaustion $(P<.001), 22 \pm 17 \%$ higher $\dot{\mathrm{V}}_{2 \text { peak }}(P=.004), 31 \pm 21 \%$ higher peak ventilation $(P=.002), 7 \pm 8 \%$ higher peak heart rate $(P=.026)$, and $28 \pm 12 \%$ higher post-exercise blood lactate concentration $(P<.001) . \dot{\mathrm{V}} \mathrm{O}_{2 \text { peak }}$ during $2 \mathrm{~L}-\mathrm{KE}$ tended to increase $(4 \pm 6 \%$; $P=.059)$, but $\mathrm{V}_{2}{ }_{2 m a x}$ during cycling was unchanged from pre- to post-training $(P=.890$; Table 1$)$.

Post-training, TL tended to have a larger thigh lean mass than CON $(7.55 \pm 0.81 \mathrm{~kg}$ vs $7.37 \pm 0.70 \mathrm{~kg}$; difference: $2.4 \pm 3.3 \% ; P=.053)$, but the quadriceps femoris muscle

T A B L E 1 Peak values (mean \pm SD) achieved during incremental exercise to exhaustion during one-legged knee extension (KE), two-legged KE, and cycling $(n=9)$

\begin{tabular}{|c|c|c|c|c|c|c|}
\hline Exercise & $\begin{array}{l}\text { Pulmonary } \\
\dot{\mathbf{V}} \mathbf{O}_{2 \text { peak }}\left(\mathrm{L} \cdot \mathrm{min}^{-1}\right)\end{array}$ & $\begin{array}{l}\text { Peak power } \\
\text { (watt) }\end{array}$ & $\begin{array}{l}\text { Time to exhaustion } \\
\text { (mm:ss) }\end{array}$ & $\begin{array}{l}\mathrm{VE}_{\text {peak }} \\
\left(\mathrm{L} \cdot \mathrm{min}^{-1}\right)\end{array}$ & $\begin{array}{l}\mathbf{H R}_{\text {peak }} \\
\text { (beats·min }^{-1} \text { ) }\end{array}$ & $\begin{array}{l}\text { Lactate } \\
\left(\mathrm{mmol} \cdot \mathrm{L}^{-1}\right)\end{array}$ \\
\hline \multicolumn{7}{|l|}{ One-legged KE } \\
\hline Trained leg (post) & $1.54 \pm 0.21^{*}$ & $64 \pm 5^{*}$ & $11: 24 \pm 1: 00^{*}$ & $65 \pm 10^{*}$ & $160 \pm 13^{*}$ & $6.0 \pm 0.7^{*}$ \\
\hline \multicolumn{7}{|l|}{ Two-legged KE } \\
\hline Post-training & $2.40 \pm 0.34 \#$ & $116 \pm 11^{*}$ & $10: 55 \pm 1: 14^{*}$ & $100 \pm 18$ & $170 \pm 9$ & $7.8 \pm 1.1$ \\
\hline \multicolumn{7}{|l|}{ Cycling } \\
\hline Pre-training & $4.30 \pm 0.37$ & $354 \pm 40$ & $8: 10 \pm 0: 53$ & $182 \pm 13$ & $193 \pm 10$ & $14.8 \pm 1.5$ \\
\hline Post-training & $4.31 \pm 0.32$ & $371 \pm 35^{*}$ & $8: 51 \pm 0: 43^{*}$ & $180 \pm 11$ & $194 \pm 8$ & $14.7 \pm 1.4$ \\
\hline
\end{tabular}

Note: $\mathrm{HR}_{\text {peak }}$, peak heart rate; $\mathrm{VE}_{\text {peak }}$, peak ventilation; $\mathrm{V}_{2 \text { peak }}$, peak oxygen uptake (pulmonary); * significantly $(P<.05)$ or \# trend toward $(0.05 \leq P \leq .10)$ difference between legs (one-legged KE) or between pre-training and post-training values (cycling and two-legged $\mathrm{KE}$ ). $\dot{\mathrm{VO}}_{2 \text { peak }}$, peak power, and $\mathrm{VE}_{\text {peak }}$ are 60 -sec averages, and $\mathrm{HR}_{\text {peak }}$ is 5-sec average. 
F I G U RE 2 Mass-specific leg blood flow (A); mass-specific $\mathrm{O}_{2}$ delivery (B); arteriovenous $\mathrm{O}_{2}$ difference $(\mathrm{C})$; and mass-specific $\mathrm{O}_{2}$ uptake (D) in the trained leg and the untrained control leg after six weeks of one-legged endurance training. Note that the trained leg and the control leg exercised simultaneously at equal absolute power output (PO). Embedded in the graphs are the ANOVA P-values indicating whether it was a main effect of the leg or an interaction effect between leg and PO. The data are means, and error bars denote SEM $(\mathrm{n}=9)$. ${ }^{*}$ Significant $(P<.05)$ and \#trend toward $(.05 \leq P \leq .10)$ difference between legs (post-hoc comparisons)

mass did not differ $(2.48 \pm 0.38 \mathrm{~kg}$ vs $2.43 \pm 0.37 \mathrm{~kg}$; difference: $2.0 \pm 3.6 \% ; P=.138$ ).

\section{2 $\quad \mathrm{O}_{2}$ extraction in the trained leg and the control leg}

At rest, $\mathrm{O}_{2}$ extraction (difference: $2.9 \pm 4.7 \%$ points; $P=.099$ ) and $\dot{\mathrm{VO}}_{2}$ (difference: $18.7 \pm 23.0 \% ; P=.080$ ) tended to be higher in TL compared with CON (Figures 2-3), while LBF was similar (difference: $8.7 \pm 24.1 \% ; P=.611$ ). During $2 \mathrm{~L}-\mathrm{KE}$ with equal absolute power output produced by both legs, $\mathrm{O}_{2}$ extraction was higher (difference: $1.7 \pm 1.6 \%$ points; $P=.010$; Figure 3A), mass-specific LBF tended to be higher (difference: $7.1 \pm 9.5 \% ; P=.051$; Figure $2 \mathrm{~A}$ ), and mass-specific $\dot{\mathrm{VO}}_{2}$ was slightly higher (difference: $9.8 \pm 9.3 \% ; P=.016$; Figure 2D) in TL compared with CON (the ANOVA main effects are given above; see Figures 2-3 for post-hoc tests). Significant interactions $($ leg $\times$ power output) were found for $\mathrm{O}_{2}$ extraction $(P=.032)$ and arteriovenous $\mathrm{O}_{2}$ difference (a-vO $\mathrm{O}_{2}$ diff; $P=.029$ ), with the largest training-induced between-leg difference at the highest power output $\left(3.2 \pm 2.2 \%\right.$ points and $7.1 \pm 4.8 \mathrm{~mL} \cdot \mathrm{L}^{-1}$, respectively; both $P<.001)$. Moreover, the subjects with the lowest $\mathrm{O}_{2}$ extraction in CON were those who had the largest betweenleg difference at the highest power output $(r=-.81 ; \mathrm{n}=9$; $P=.008)$, that is, the largest training effect. The increased $\mathrm{O}_{2}$ extraction was not caused by a right-shifted ODC, since the $\mathrm{P}_{50} \mathrm{O}_{2}$ was slightly higher in $\mathrm{CON}(P=.005)$ due to a lower femoral venous $\mathrm{pH}$ (Table 2; $P=.007$ ).

\section{3 | Muscle $\mathrm{O}_{2}$ conductance}

The larger $\mathrm{O}_{2}$ extraction resulted in lower femoral venous $\mathrm{PO}_{2}(P=.004)$ and calculated mean capillary $\mathrm{PO}_{2}(P=.003)$ in TL than in CON (Table 2). According to the Fick law of diffusion, it can be estimated that the recruitment of $\mathrm{D}_{\mathrm{M}} \mathrm{O}_{2}$ was $13.9 \pm 8.3 \%$ larger in TL than in CON $(P=.001$; Figure 3B). The equilibration index $\mathrm{Y}$, which quantitatively describes diffusion vs perfusion limitations (where $\mathrm{Y}<0.1$ indicates pure diffusion limitation, $0.1<\mathrm{Y}<3$ indicates
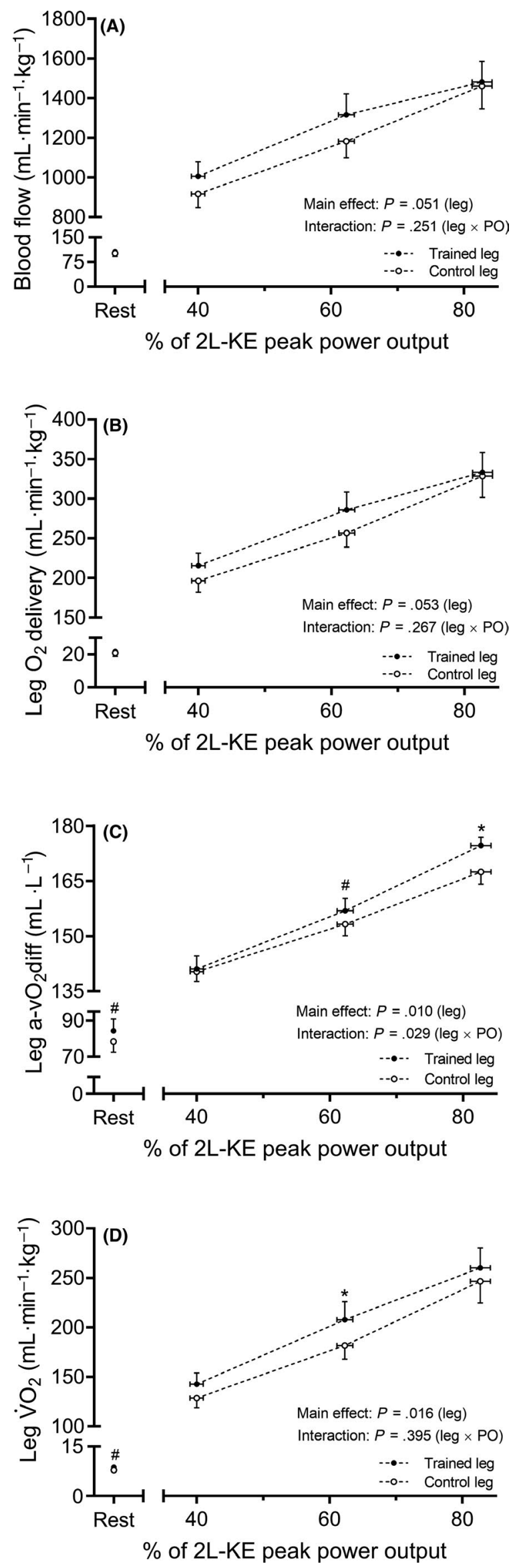

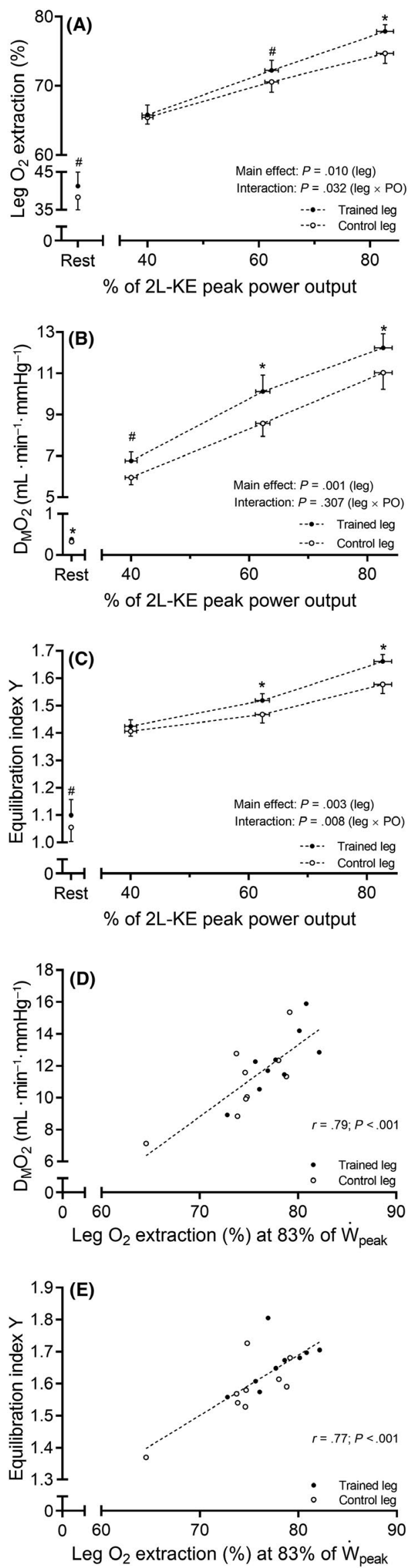

F I G URE 3 Leg $\mathrm{O}_{2}$ extraction (A); recruitment of muscle $\mathrm{O}_{2}$ conductance $\left(\mathrm{D}_{\mathrm{M}} \mathrm{O}_{2}\right)(\mathrm{B})$; and the equilibration index $\mathrm{Y}(\mathrm{C})$ in the trained leg and the untrained control leg after 6 weeks of onelegged endurance training. The equilibration index Y quantitatively describes diffusion vs perfusion limitations (where $\mathrm{Y}<0.1$ indicates pure diffusion limitation, $0.1<\mathrm{Y}<3$ indicates mixed perfusiondiffusion limitation, and $\mathrm{Y}>3$ indicates pure perfusion limitation), that is, the diffusion limitation is lower in the trained leg. The data are means, and error bars denote SEM $(\mathrm{n}=9)$. *Significant $(P<.05)$ and \#trend toward $(0.05 \leq P \leq .10)$ difference between legs (post-hoc comparisons). In graphs $\mathrm{D}$ and $\mathrm{E}$, the relationships between leg $\mathrm{O}_{2}$ extraction and the recruitment of $\mathrm{D}_{\mathrm{M}} \mathrm{O}_{2}$ and the equilibration index $\mathrm{Y}$ are displayed, respectively

mixed perfusion-diffusion limitation, and $\mathrm{Y}>3$ indicates pure perfusion limitation), ${ }^{29}$ was higher in TL (mean values for $40 \%-83 \%$ of $\dot{\mathrm{W}}_{\text {peak }}: 1.53 \pm 0.07$ vs $1.48 \pm 0.08 ; P=.003$; Figure $3 \mathrm{C}$ ) and increased more with power output than in CON (values at $83 \%$ of $\dot{\mathrm{W}}_{\text {peak }}: 1.66 \pm 0.08$ vs $1.58 \pm 0.10$; interaction: $P=.008$; Figure $3 \mathrm{C}$ ). Therefore, the resistance to $\mathrm{O}_{2}$ diffusion from the capillaries to cytochrome-c-oxidase was lower in TL than in CON, and the between-leg difference increased with power output. Furthermore, at the highest power output, leg $\mathrm{O}_{2}$ extraction correlated with the recruitment of $\mathrm{D}_{\mathrm{M}} \mathrm{O}_{2}$ and the equilibration index $\mathrm{Y}$ (both $P<.001$; Figure 3D-E).

\section{4 | Skeletal muscle adaptations}

Before training, none of the analyzed mitochondrial enzymes differed between legs $(P \geq .56)$. After training, TL expressed a higher protein content of citrate synthase (45 $\pm 29 \% ; P<.001)$, COX-IV (44 $\pm 46 \% ; P=.044)$, and HAD (35 $\pm 28 \% ; P=.007$; Figure 4). After training, the capillary-to-fiber ratio was $18 \pm 23 \%(P=.031)$ higher in TL than in CON and the capillary density tended to be higher $(12 \pm 17 \% ; P=.067$; Table 3$)$.

\section{5 | Relationships between muscle morphology and in vivo measurements}

At the highest power output ( $83 \%$ of $\dot{\mathrm{W}}_{\text {peak }}$ ), the between-leg difference in $\mathrm{O}_{2}$ extraction correlated with the between-leg ratio of citrate synthase $(r=.72 ; \mathrm{n}=9 ; P=.028)$ and COX-IV $(r=.73 ; \mathrm{n}=9 ; P=.024)$, as well did the two enzymes combined into an average $(P=.010 ; \mathrm{n}=9 ;$ Figure $5 \mathrm{~A})$. When the mitochondrial protein contents were standardized to a human control sample, to allow for comparisons across subjects, COX-IV $(r=.57 ; \mathrm{n}=18 ; P=.013)$, citrate synthase $(r=.47$; $\mathrm{n}=18 ; P=.049)$, and their average correlated with leg $\mathrm{O}_{2}$ extraction $(P=.011 ; \mathrm{n}=18$; Figure $5 \mathrm{C})$. The average of citrate synthase and COX-IV standardized to a human control 
sample also showed a close relationship with the recruitment of $\mathrm{D}_{\mathrm{M}} \mathrm{O}_{2}$ at $83 \%$ of $\dot{\mathrm{W}}_{\text {peak }}(r=.74 ; \mathrm{n}=18 ; P<.001)$. Leg $\mathrm{O}_{2}$ extraction correlated with the capillary-to-fiber ratio $(P=.029 ; \mathrm{n}=18$; Figure 5D). However, no relationship was evident when the between-leg difference in capillary-to-fiber ratio was plotted against the between-leg difference in oxygen extraction $(P=.965 ; \mathrm{n}=9$; Figure $5 \mathrm{~B})$, potentially indicating a more important role of the increased citrate synthase and COX-IV protein content than increased capillary-to-fiber ratio on the improved $\mathrm{O}_{2}$ extraction capacity.

\section{4 | DISCUSSION}

In the present study, we show that the primary mechanism by which endurance training increases $\mathrm{O}_{2}$ extraction during small muscle mass exercise is by elevating the muscle oxidative capacity, which facilitates a more efficient $\mathrm{O}_{2}$ diffusion from the capillaries to the mitochondria. This was especially evident during high-intensity exercise that exploits a large fraction of the muscle oxidative capacity. In support, significant between-leg differences in mitochondrial enzyme contents (35\%-45\%) were observed after the training period, which was associated with the between-leg difference in $\mathrm{O}_{2}$ extraction during high-intensity exercise. The recruitment of $\mathrm{D}_{\mathrm{M}} \mathrm{O}_{2}$ and the equilibration index $\mathrm{Y}$ were higher in the trained leg than in the control leg, indicating reduced resistance to $\mathrm{O}_{2}$ diffusion, with these variables also displaying strong relationships with leg $\mathrm{O}_{2}$ extraction.

\section{1 $\quad$ Endurance training increases $\mathrm{O}_{2}$ extraction}

During maximal exercise with a small muscle mass (eg, 1L-KE), the mass-specific blood flow and $\mathrm{V}_{2}$ are high. Consequently, the oxidative capacity of the exercising muscles is close to being fully exploited, ${ }^{14}$ which may restrict $\mathrm{O}_{2}$ diffusion from the capillaries to cytochrome-c-oxidase. ${ }^{5}$ Therefore, we hypothesized that elevating the muscle oxidative capacity with endurance training would enhance the recruitment of $\mathrm{D}_{\mathrm{M}} \mathrm{O}_{2}$ and increase $\mathrm{O}_{2}$ extraction when exercising with a small muscle mass. In support of this hypothesis, the $\mathrm{O}_{2}$ extraction was significantly higher in TL than in CON during 2L-KE exercise at high, but not at low power outputs. Importantly, the two legs were exercising with the same power outputs, indicating that the between-leg difference was exclusively caused by the difference in training status. A difference in leg $\mathrm{O}_{2}$ extraction at high but not at low power outputs has been reported after one-legged training before ${ }^{17}$ and indicates that the effect of training on $\mathrm{O}_{2}$ extraction is intensity-dependent and most evident when most of the muscle oxidative capacity is exploited.
Previous studies assessing the trained and non-trained legs separately during $1 \mathrm{~L}-\mathrm{KE}$ have reported increased ${ }^{9,10,35,36}$ or unchanged ${ }^{13,37,38}$ leg $\mathrm{O}_{2}$ extraction after endurance training. Most of the studies reporting no improvement of $\mathrm{O}_{2}$ extraction employed exercise protocols designed to assess vascular function at low-to-moderate intensities. ${ }^{13,38}$ This agrees with our findings since no significant enhancement of $\mathrm{O}_{2}$ extraction was observed at low and moderate exercise intensities also in the present study. Similarly, Klausen and coworkers found an unchanged leg a- $\mathrm{vO}_{2}$ diff during submaximal exercise but found a $7 \mathrm{~mL} \cdot \mathrm{L}^{-1}$ increase during maximal one-legged cycling after 8 weeks of one-legged endurance training. ${ }^{39}$ The latter concurs with the study by Boushel and coworkers in which maximal exercise arm $\mathrm{O}_{2}$ extraction was raised from $62 \%$ to $68 \%$ after low-intensity training. ${ }^{15}$ During arm cycling, the active muscle mass is small $(\sim 6 \mathrm{~kg})$ and the mass-specific blood flow is large..$^{40}$ Thus, our results combined with previous studies strongly suggest that $\mathrm{O}_{2}$ extraction during small muscle mass exercise is improved after endurance training, particularly when the exercise intensity is close to maximal.

We expected a larger between-leg difference in $\mathrm{O}_{2}$ extraction when TL and CON were assessed simultaneously during $2 \mathrm{~L}-\mathrm{KE}$ compared with during two-legged cycling because of the more limited muscle oxidative capacity and lower $\mathrm{O}_{2}$ extraction in this exercise model. ${ }^{5}$ However, a similar pattern was observed in the present study and Rud et al (2012), with no difference at low-intensity exercise, a tendency to difference at moderate-intensity exercise, and a significant difference at high-intensity exercise. ${ }^{17}$ The between-leg differences in $\mathrm{O}_{2}$ extraction $(3.2 \%$ vs $3.5 \%$ points) and a- $\mathrm{vO}_{2} \operatorname{diff}\left(7.1 \mathrm{vs} 6.6 \mathrm{~mL} \cdot \mathrm{L}^{-1}\right)$ were also almost identical in the two studies, indicating no amplifying effect when comparing trained and untrained muscles simultaneously during small vs large muscle mass exercise. However, the total training volume was larger in Rud et al (2012) than in the present study (4 sessions.week ${ }^{-1}$ over 7 weeks, with the session duration progressively increasing from 40 to 100 minutes), and without an assessment within the same subjects after similar training, no definite conclusion can be given.

The effect of endurance training on $\mathrm{O}_{2}$ extraction during large muscle mass exercise remains controversial ${ }^{14,17,18,41}$ since the muscle oxidative capacity is far from being fully utilized and is therefore not considered a limiting factor for muscle $\mathrm{O}_{2}$ extraction and $\dot{\mathrm{VO}}_{2 \text { max }}{ }^{14}$ This agrees with a recent meta-analysis reporting no significant change in systemic a- $\mathrm{vO}_{2}$ diff after endurance training, as calculated using the Fick equation from the measured $\mathrm{V}_{2 \text { max }}$ and $\dot{\mathrm{Q}}_{\max }$ (mostly estimated from non-invasive methods). ${ }^{16} \mathrm{In}$ contrast, some experimental data indicate otherwise when $\mathrm{O}_{2}$ extraction is calculated directly from a- $\mathrm{vO}_{2}$ diff in the exercising limb (arterial and venous catheters). For example, 
T A B L E 2 Blood variables during two-legged knee extension exercise with the trained (TL) and the control (CON) leg working at the same absolute power output (mean $\pm \mathrm{SD})$

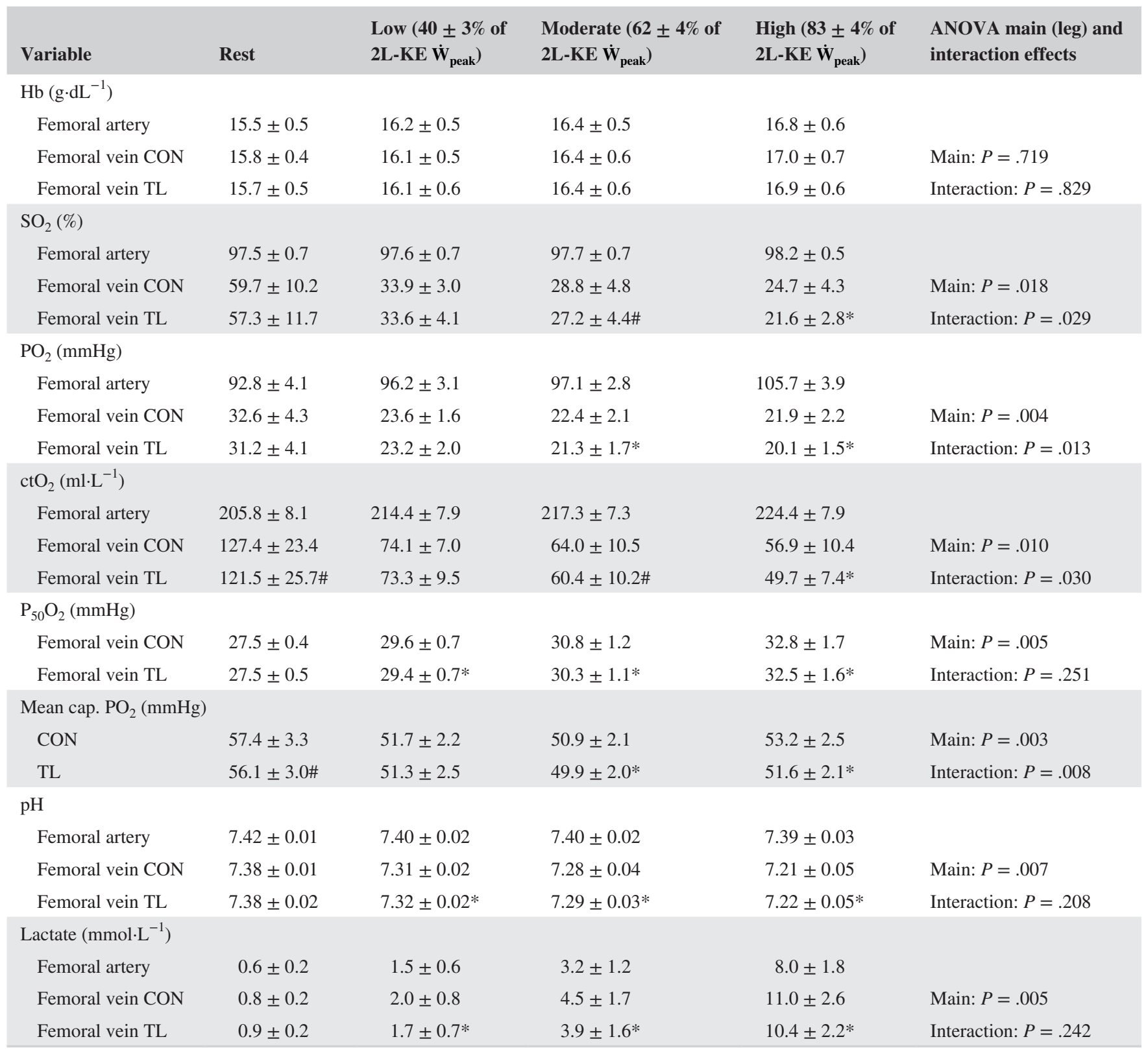

Note: $\mathrm{n}=9$; the main effect indicates the difference between legs, and the interaction effect is between legs and power output (two-way repeated-measures ANOVA). Post-hoc tests identify significant $(* P<.05)$ or trend toward $(\# 0.05 \leq P \leq .10)$ differences between legs within each workload. A paired sample $t$ test analyzed the difference between legs during rest.

Roca and coworkers ${ }^{18}$ found that leg $\mathrm{O}_{2}$ extraction increased from $72 \%$ to $82 \%$ during maximal cycling after sedentary subjects underwent nine weeks of intense endurance training $\left(\dot{\mathrm{V}}_{2 \max }\right.$ rose from 37 to $\left.51 \mathrm{~mL} \cdot \mathrm{kg}^{-1} \cdot \mathrm{min}^{-1}\right)$. After several years of training, leg $\mathrm{O}_{2}$ extraction is reported to be as high as $91 \%-93 \%$ in competitive cyclists and cross-country skiers $\left(\dot{\mathrm{VO}}_{2 \text { max }}: 65-72 \mathrm{~mL} \cdot \mathrm{kg}^{-1} \cdot \mathrm{min}^{-1}\right){ }^{27,42}$ Thus, even though conflicting evidence exists on whether systemic a- $\mathrm{vO}_{2}$ diff increases after short-term endurance training during large muscle mass exercise, compelling evidence suggests that the $\mathrm{O}_{2}$ extraction increases when measured directly with arterial and venous blood sampling in the exercising limbs. ${ }^{15,17,18,21,39,43}$

\subsection{1 | Oxidative capacity of the leg}

In a previous study, ${ }^{17}$ increased leg $\mathrm{O}_{2}$ extraction coincided with increased muscle oxidative capacity (citrate synthase activity) after endurance training. Likewise, muscle oxidative capacity is shown to be important for $\mathrm{O}_{2}$ extraction in the isolated rat hind limb, especially when pump-perfused 


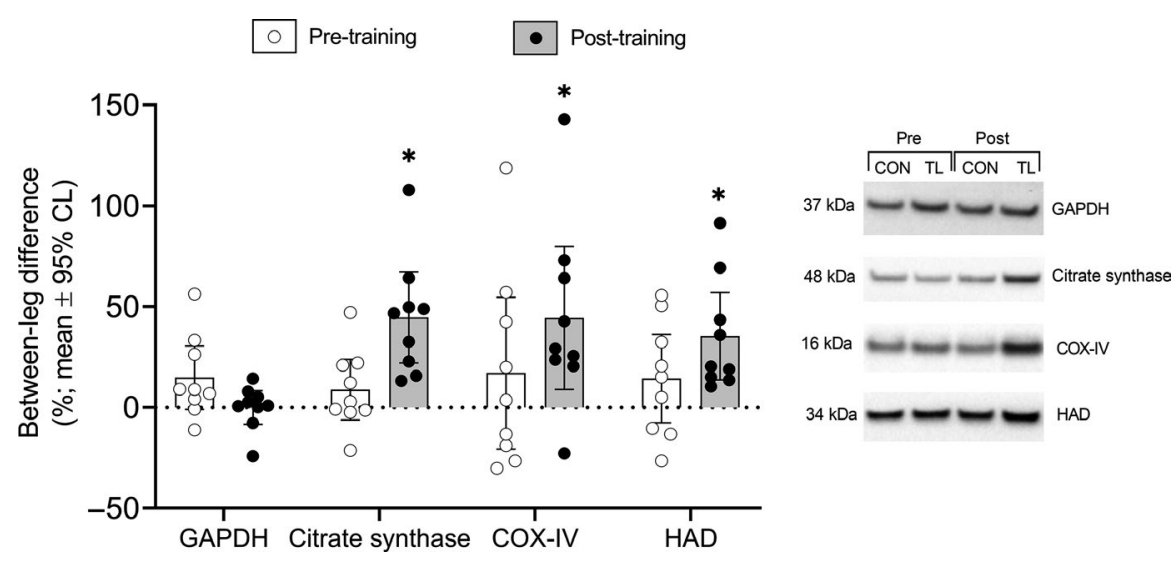

F I G U RE 4 The protein content of the mitochondrial enzymes citrate synthase, cytochrome-c-oxidase subunit 4 (COX-IV), and hydroxyacylCoA dehydrogenase (HAD) along with the loading control glyceraldehyde 3-phosphate dehydrogenase (GAPDH). The individual and mean values are presented as percentage between-leg differences (trained leg - control leg) at pre-training and post-training $(\mathrm{n}=9)$. Error bars denote 95\% confidence limits $(C L)$. *Significant difference $(P<.05)$ between legs at post-training, that is, at the time of the invasive experiment.

Representative blots of the four proteins along with their observed molecular weights are presented

T A B L E 3 Vastus lateralis muscle composition in the trained leg and the control leg post-training (mean $\pm \mathrm{SD}$ )

\begin{tabular}{|c|c|c|c|}
\hline Variable & Control leg & Trained leg & $P$-value \\
\hline \multicolumn{4}{|c|}{ Fiber size $\left(\mu \mathrm{m}^{2}\right)$} \\
\hline All fibers & $4954 \pm 1063$ & $5187 \pm 1167$ & .396 \\
\hline Type I & $4510 \pm 1156$ & $4870 \pm 1050$ & .315 \\
\hline Type II & $5245 \pm 1321$ & $5487 \pm 1134$ & .394 \\
\hline \multicolumn{4}{|l|}{ Fiber type (\%) } \\
\hline Type I & $41 \pm 7$ & $45 \pm 10$ & .212 \\
\hline Type II & $59 \pm 7$ & $55 \pm 10$ & .212 \\
\hline \multicolumn{4}{|c|}{ Capillaries around a fiber } \\
\hline All fibers & $3.1 \pm 0.5$ & $3.5 \pm 0.8$ & .122 \\
\hline Type I & $3.3 \pm 0.5$ & $3.6 \pm 0.7$ & .170 \\
\hline Type II & $3.1 \pm 0.5$ & $3.5 \pm 0.8$ & .138 \\
\hline $\begin{array}{l}\text { Capillaries/ } \\
\mathrm{mm}^{2}\end{array}$ & $280 \pm 59$ & $311 \pm 75$ & .067 \\
\hline $\begin{array}{l}\text { Capillary-to- } \\
\text { fiber ratio }\end{array}$ & $1.35 \pm 0.26$ & $1.58 \pm 0.33$ & .031 \\
\hline
\end{tabular}

Note: $\mathrm{n}=9$.

with high muscle blood flow and $\mathrm{O}_{2}$ delivery ${ }^{20,44,45}$ that mimic the situation observed during small muscle mass exercise in humans. In the present study, the between-leg difference in mitochondrial enzymes (citrate synthase, COX-IV, and the average of these two markers) significantly correlated with the difference in $\mathrm{O}_{2}$ extraction. Therefore, it is likely that the enhanced muscle oxidative capacity in TL was the primary contributing factor to the improved $\mathrm{O}_{2}$ extraction, particularly since the between-leg difference in capillary density was similar to that of LBF, indicating that the erythrocyte capillary mean transit time (MTT) was similar in both legs.

It has been suggested that the surface area between the capillaries and the myocytes is of particular importance for $\mathrm{D}_{\mathrm{M}} \mathrm{O}_{2}$ and $\mathrm{O}_{2}$ extraction. ${ }^{46}$ Therefore, the increased capillary-to-fiber ratio may have played a role in increasing the $\mathrm{O}_{2}$ extraction. However, new evidence suggests that the muscle possesses a functional reserve in $\mathrm{D}_{\mathrm{M}} \mathrm{O}_{2}$ that is utilized when breathing hypoxic gas during incremental exercise to exhaustion on the cycle ergometer ${ }^{28}$ and the $1 \mathrm{~L}-\mathrm{KE}$ ergometer. ${ }^{2}$ These studies indicate that greater $\mathrm{D}_{\mathrm{M}} \mathrm{O}_{2}$ can be achieved with the same capillary-to-fiber ratio during exercise in hypoxia, meaning that the capillary-to-fiber ratio is not the predominant factor limiting $\mathrm{D}_{\mathrm{M}} \mathrm{O}_{2}$ in healthy men. This interpretation is further supported by our current findings since the between-leg difference in the capillary-to-fiber ratio was not associated with the between-leg difference in $\mathrm{O}_{2}$ extraction (Figure 5B). Most likely, it is the interplay between muscle oxidative capacity, mitochondrial p50, the tissue $\mathrm{O}_{2}$ consumption (and by extension, the mitochondrial activation), MTT, perfusion-metabolism matching, and $\mathrm{O}_{2}$ delivery that establishes the ceiling for $\mathrm{O}_{2}$ extraction. ${ }^{5,27,28,47}$ Moreover, the subsarcolemmal mitochondrial population increases relatively more than the intermyofibrillar population after endurance training. ${ }^{48,49}$ Although this population is assumed to be more important for the ATP demands of membrane ion and substrate transporters than for the myofibrils, increased subsarcolemmal mitochondrial clusters may amplify the $\mathrm{O}_{2}$ concentration gradient and thus $\mathrm{O}_{2}$ diffusion across the sarcolemma. ${ }^{50,51}$ It cannot be excluded that such an adaptation may have contributed to the reduced resistance to $\mathrm{O}_{2}$ diffusion and increased $\mathrm{O}_{2}$ extraction in TL.

In contrast, a few studies have challenged the idea that the oxidative capacity of the muscles is important for $\mathrm{O}_{2}$ extraction in humans. For example, after bed rest, systemic $\mathrm{O}_{2}$ extraction 

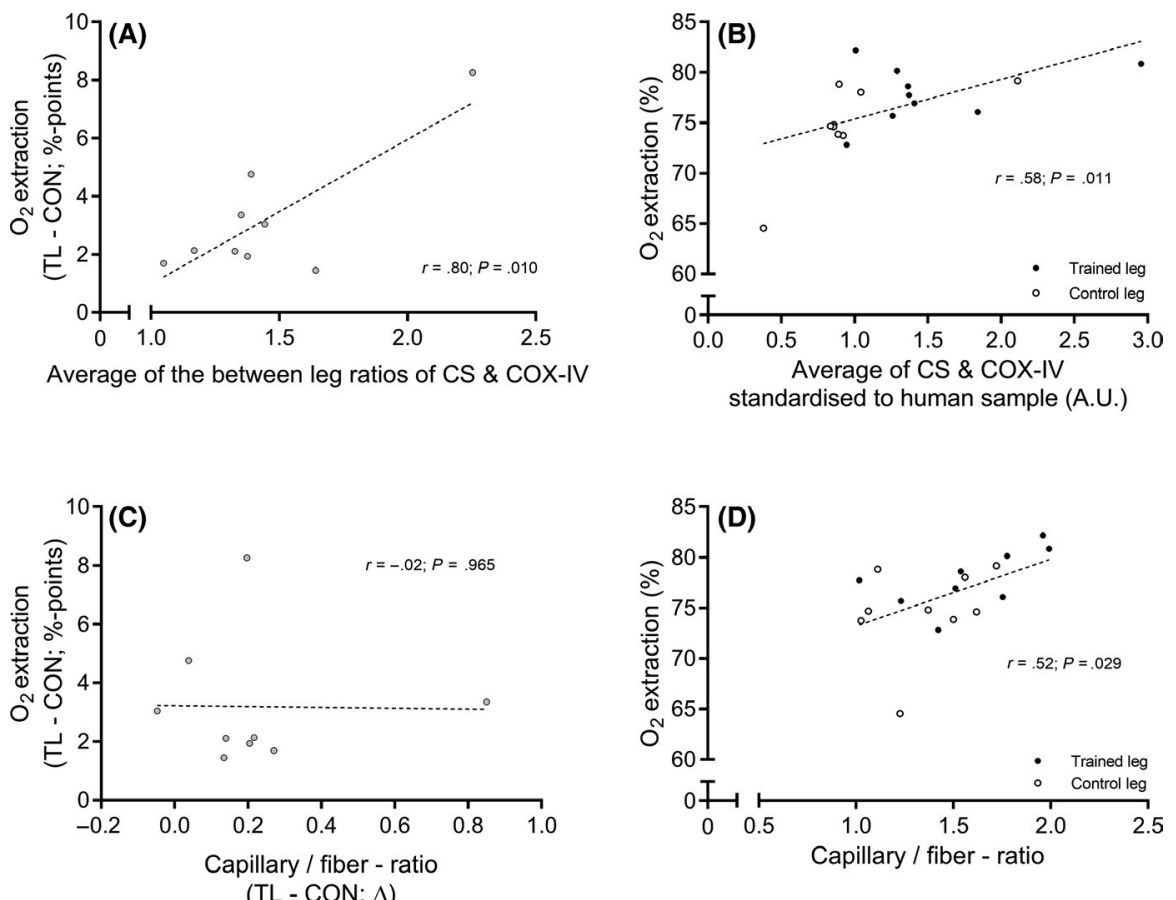

F I G URE 5 Data are from the highest power output. The relationship between the between-leg difference in $\mathrm{O}_{2}$ extraction and the betweenleg ratio of mitochondrial protein content (presented as an average of the between-leg ratios of CS and COX-IV: $\left[\left(\mathrm{CS}_{\mathrm{TL}} / \mathrm{CS}_{\mathrm{CON}}\right)+(\mathrm{COX}-\mathrm{IV} \mathrm{TL} /\right.$ $\left.\left.\mathrm{COX}-\mathrm{IV}_{\mathrm{CON}}\right)\right] / 2$; Figure $5 \mathrm{~A}$ ) or the between-leg difference in the capillary-to-fiber ratio (Figure 5B). In Figure 5C, the mitochondrial protein content was standardized to a human control sample, which was loaded on each gel to allow for between-subject comparisons, and the individual values (presented as arbitrary units; $\mathrm{AU}$ ) were plotted against $\mathrm{O}_{2}$ extraction. In Figure 5D, the capillary-to-fiber ratio is plotted against $\mathrm{O}_{2}$ extraction. CS, citrate synthase; COX-IV, cytochrome-c-oxidase subunit 4; TL, trained leg; CON, control leg

is maintained during whole-body exercise even though the muscle oxidative capacity and $\dot{\mathrm{VO}}_{2 \max }$ are substantially reduced. ${ }^{52,53}$ Therefore, it is argued that the muscles have a substantial reserve of oxidative capacity and that $\dot{\mathrm{VO}}_{2 \text { max }}$ is almost exclusively limited by $\mathrm{O}_{2}$ delivery. ${ }^{14}$ This might be true during large muscle mass exercise but is not directly transferable to small muscle mass exercise, where this oxidative reserve capacity is exploited. ${ }^{7}$ Nevertheless, even during large muscle mass exercise, muscle $\mathrm{V}_{2}$ is multifactorial. ${ }^{54,55}$ In this context, by decreasing $\dot{\mathrm{Q}}_{\max }$ as a result of bed rest, the decreased blood flow to the exercising muscles would prolong capillary MTT substantially since bed rest only causes a minor change in the capillary density, ${ }^{52,53}$ ultimately favoring $\mathrm{Hb}-\mathrm{O}_{2}$ off-loading that potentially compensates for the detrimental effects of reduced mitochondrial volume density. The same response can be seen when decreasing $\dot{\mathrm{Q}}_{\max }$ and LBF during maximal exercise with $\beta$-adrenergic blockade, which increases systemic and leg a-vO${ }_{2}$ diff through increased MTT. ${ }^{56,57}$ Therefore, training-induced improvements in whole-body $\dot{\mathrm{V}}_{2 \text { max }}$ in parallel with increased $\dot{\mathrm{Q}}_{\max }$ and muscle oxidative capacity may not always result in improved $\mathrm{O}_{2}$ extraction if MTT is substantially reduced caused by elevated muscle blood flow. This is substantiated by the positive relationship between the ratio of OXPHOS/ $\mathrm{O}_{2}$ delivery and the leg $\mathrm{O}_{2}$ extraction, ${ }^{5}$ meaning that the balance between muscle oxidative capacity and blood flow (ie, oxidative capacity and MTT) is more critical for $\mathrm{O}_{2}$ extraction than any of these factors alone.

\subsubsection{Kinetics of $\mathrm{O}_{2}$ off-loading from $\mathrm{Hb}$}

The off-loading of $\mathrm{O}_{2}$ from $\mathrm{Hb}$ at the tissue level is facilitated by increased temperature, decreased $\mathrm{pH}$, and increased $\mathrm{PCO}_{2}$, which causes a right shift in the ODC and lowers the $\mathrm{Hb}-\mathrm{O}_{2}$ affinity. ${ }^{58}$ Hence, a close relationship between $\mathrm{O}_{2}$ extraction and $\mathrm{P}_{50} \mathrm{O}_{2}$ has been found in humans during exercise. ${ }^{27}$ Moreover, increased $\mathrm{O}_{2}$ extraction and $\dot{\mathrm{V}}_{2 \max }$ were found in pump-perfused dog muscle when the ODC was right-shifted by artificially elevating $\mathrm{P}_{50} \mathrm{O}_{2}$ from its normal value 32 to $53 \mathrm{mmHg} .{ }^{59}$ In the present study, $\mathrm{P}_{50} \mathrm{O}_{2}$ increased alongside with $\mathrm{O}_{2}$ extraction when increasing the power output in both legs, indicating that elevated $\mathrm{P}_{50} \mathrm{O}_{2}$ contributed to more efficient $\mathrm{O}_{2}$ offloading and $\mathrm{O}_{2}$ extraction during high-intensity exercise. However, the right-shifted ODC was less pronounced in TL than in CON, excluding $\mathrm{P}_{50} \mathrm{O}_{2}$ as an explanatory factor for the improvement of $\mathrm{O}_{2}$ extraction. In this context, for a given $\mathrm{P}_{50} \mathrm{O}_{2}$, TL was, however, able to extract more $\mathrm{O}_{2}$ (Figure 6), likely because of the enhanced muscle oxidative capacity and larger recruitment of $\mathrm{D}_{\mathrm{M}} \mathrm{O}_{2}$. 


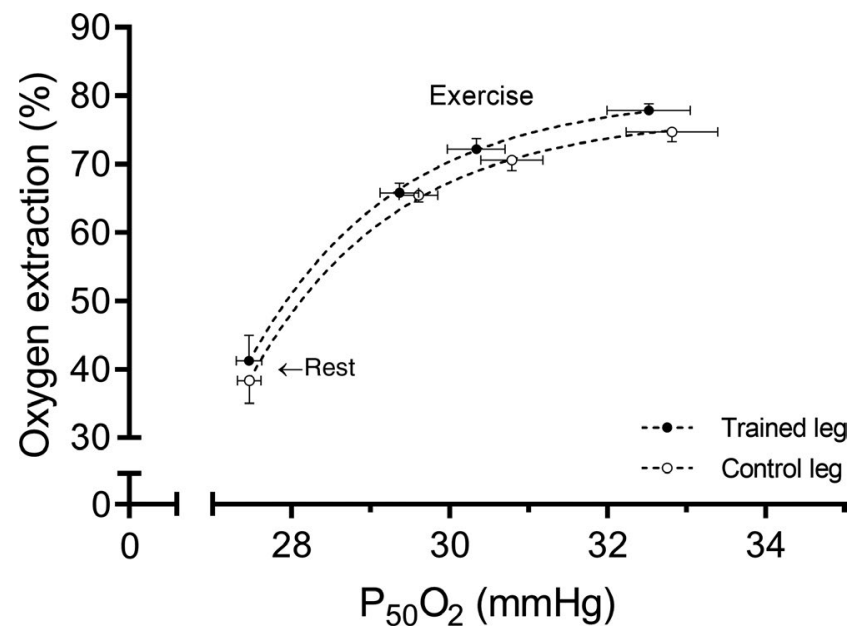

F I G URE $6 \mathrm{O}_{2}$ extraction during rest and exercise as a function of the partial pressure of $\mathrm{O}_{2}$ that causes hemoglobin to be $50 \%$ saturated $\left(\mathrm{P}_{50} \mathrm{O}_{2}\right)$. Note that a high $\mathrm{P}_{50} \mathrm{O}_{2}$ is beneficial for $\mathrm{O}_{2}$ offloading and that the trained leg had the highest $\mathrm{O}_{2}$ extraction despite having a lower $\mathrm{P}_{50} \mathrm{O}_{2}$ than the control leg

\subsection{3 | Oxygen diffusion was more efficient in the trained leg}

The lower femoral venous $\mathrm{PO}_{2}$ and mean capillary $\mathrm{PO}_{2}$ were achieved through enhanced $\mathrm{O}_{2}$ extraction and resulted in higher recruitment of $\mathrm{D}_{\mathrm{M}} \mathrm{O}_{2}$ in TL (Figure 7). In this context, by applying the Piiper and Scheid model, we calculated the equilibration index $\mathrm{Y}$, which quantitatively describes diffusion vs perfusion limitations. ${ }^{29}$ The equilibration index $\mathrm{Y}$ increased with power output in both legs, indicating that perfusion and diffusion limitations were rising and decreasing, respectively, as power output was elevated. Interestingly, the equilibration index $\mathrm{Y}$ increased more with power output in TL (Figure 3C), indicating that the training-induced reduction in diffusion limitations was more marked during high-intensity exercise. Thus, it seems that the benefit from increasing the muscle oxidative capacity is more apparent when the mitochondria operate closer to their maximal oxidative capacity. In agreement, a significant correlation between the protein content of mitochondrial enzymes (the average of citrate synthase and COX-IV) and the recruitment of $\mathrm{D}_{\mathrm{M}} \mathrm{O}_{2}$ $(r=.74 ; P<.001)$ and the equilibration index $\mathrm{Y}(r=.50$; $\mathrm{n}=18 ; P=.034)$ was observed at the highest power output, potentially allowing for the maintenance of an efficient $\mathrm{O}_{2}$ diffusion and $\mathrm{O}_{2}$ extraction even in the most distal capillary regions with the lowest $\mathrm{PO}_{2}$ gradients.

\section{2 $\quad$ Blood flow and $\mathrm{O}_{2}$ delivery}

LBF and $\mathrm{O}_{2}$ delivery were slightly higher in TL than in $\mathrm{CON}$, and although this effect was not statistically significant, it deserves some attention. The release of ATP from

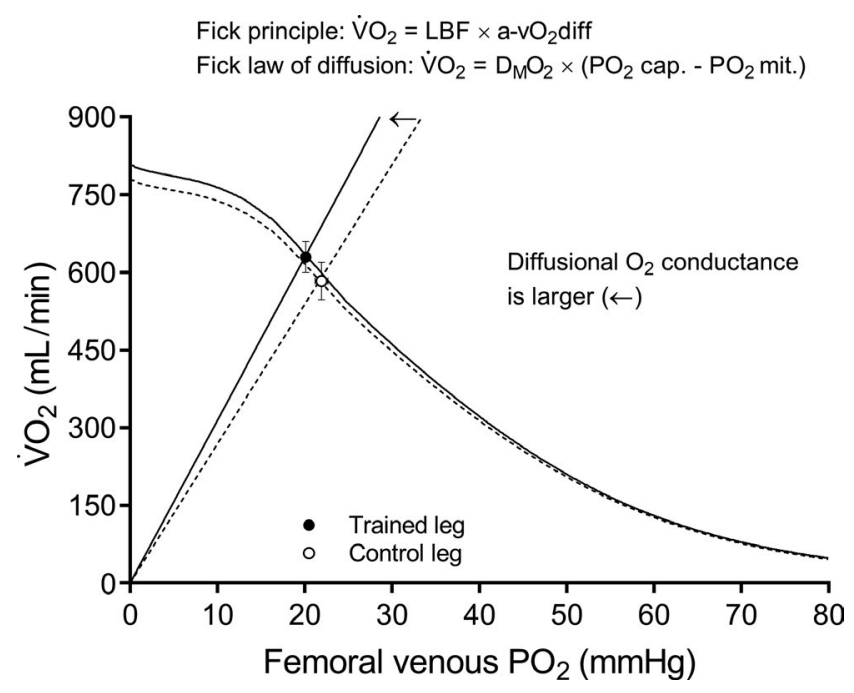

F IG URE 7 The $\mathrm{V}_{2}$ in the trained leg and the control leg is plotted as a function of femoral venous $\mathrm{PO}_{2}$ at $83 \%$ of peak power output (filled symbols). The sigmoid curves represent the $\dot{\mathrm{VO}}_{2}$ (the trained and the control legs are illustrated by a whole line or a dotted line, respectively) determined by the Fick principle ( $\mathrm{LBF} \times \mathrm{a}-\mathrm{vO}_{2}$ diff). The lines from the origin through the data points represent the Fick law of diffusion. Note that a larger diffusional $\mathrm{O}_{2}$ conductance $(\leftarrow)$ is recruited in the trained leg compared with the control leg. $\mathrm{VO}_{2}$, oxygen uptake; $\mathrm{LBF}$, leg blood flow; a- $\mathrm{vO}_{2}$ diff, arteriovenous $\mathrm{O}_{2}$ difference; $\mathrm{D}_{\mathrm{M}} \mathrm{O}_{2}$, muscle $\mathrm{O}_{2}$ conductance; $\mathrm{PO}_{2}$, the partial pressure of $\mathrm{O}_{2} ; \mathrm{PO}_{2}$ cap., mean capillary $\mathrm{PO}_{2} ; \mathrm{PO}_{2}$ mit., $\mathrm{PO}_{2}$ of the mitochondria

erythrocytes acts as a potent vasodilator via purinergic receptors in vascular endothelial cells, ultimately leading to nitric oxide and prostacyclin formation, followed by smooth muscle cell relaxation. ${ }^{60}$ It has been demonstrated that erythrocyte ATP release is inhibited in the presence of high lactate concentration ${ }^{61}$ and accelerated by low $\mathrm{PO}_{2}{ }^{62}$ Thus, the lower femoral venous $\mathrm{PO}_{2}$ and lower lactate concentration during exercise in TL may have facilitated larger ATPmediated vasodilation compared with $\mathrm{CON}$, which could have facilitated the slightly higher LBF. The fact that LBF was very similar at the highest exercise intensity may question these speculations. However, sympathetic vasoconstrictor activity is higher at high-intensity exercise and may dominate over ATP-mediated vasodilation, even if exercise training also has been shown to improve functional sympatholysis. ${ }^{13,63}$ However, to study the mechanisms regulating skeletal muscle blood flow was beyond the scope of the present investigation.

Other researchers have reported no change or a small reduction in submaximal LBF after one-legged training. ${ }^{9,13,39}$ In most of these studies, the effect of training has been assessed separately in the trained leg and the non-trained control leg, using the 1L-KE or one-legged cycling models. At submaximal exercise intensities, decreased heart rate, mean arterial pressure, and, hence, perfusion pressure have 
been found when exercising after training. ${ }^{9,13,39}$ This is most likely caused by a reduced influence of the metaboreflex and therefore a reduced sympathetic activation during submaximal exercise after training. Decreased perfusion pressure has been accompanied by increased vascular conductance. ${ }^{37,39}$ In the present study, both legs were exercised simultaneously and therefore had the same perfusion pressure resulting in a slightly higher LBF in TL due to a larger vascular conductance (data not presented). To our knowledge, only three previous investigations have assessed the hemodynamic response while exercising with one trained leg and one control leg simultaneously, ${ }^{17,21,22}$ of which only one of these investigations balanced the power output between legs. ${ }^{17}$ In this study, no difference in LBF was found at low-to-moderate power outputs, but it was found a tendency to higher LBF and a significantly higher leg a- $\mathrm{vO}_{2}$ diff in $\mathrm{TL}$ at high exercise intensity, in agreement with our results.

In conclusion, the present study confirms that endurance training increases $\mathrm{O}_{2}$ extraction during exercise involving a small muscle mass in humans. This was achieved primarily through increased muscle oxidative capacity and larger recruitment of $\mathrm{D}_{\mathrm{M}} \mathrm{O}_{2}$ that reduced the restrictions on $\mathrm{O}_{2}$ diffusion from the capillaries to the mitochondria. The increased capillary-to-fiber ratio may also have played a secondary role in increasing the $\mathrm{O}_{2}$ extraction by increasing the surface area between the capillaries and the myocytes.

\section{5 | PERSPECTIVE}

A major aim of endurance training is to enhance exercise capacity by improving $\mathrm{O}_{2}$ utilization, which can be achieved by acting on the principal limiting factors. The present findings indicate that a small muscle mass exercise (knee extension, in the present study) can efficiently improve exercise capacity and $\mathrm{O}_{2}$ extraction with training by a mechanism tightly connected to enhancement of mitochondrial proteins (here used as a proxy of mitochondrial volume). This effect seems more important than the accompanying change in the capillary-to-fiber ratio. Of particular interest, increased muscle oxidative capacity did not translate into improved $\mathrm{O}_{2}$ extraction during low-intensity exercise, that is, when the MTT is longer. At higher exercise intensities which are associated with greater mitochondrial activation and lower time for $\mathrm{Hb}-\mathrm{O}_{2}$ off-loading, the benefit from an endurance training-induced increase in muscle oxidative capacity on $\mathrm{O}_{2}$ extraction is most prominent. Our results indicate that to enhance exercise capacity during small muscle mass exercise, increased mitochondrial oxidative capacity is likely mandatory in subjects with lowto-moderate fitness levels. This has important implications for people training while taking mitochondrion-toxic drugs such as metformin or statins, which may blunt the expected mitochondrial biogenesis.

\section{ACKNOWLEDGMENTS}

The authors would like to thank the volunteers for their participation and cooperation during the study. A special thank is given to Lasse Gliemann for an introduction to blood flow measurements using ultrasound Doppler. In addition, we would like to thank Kristoffer Cumming, Hege Nymo Østgaard, Jan Fredrik Bævre, Svein Leirstein, and Camilla Høivik Carlsen for valuable assistance during the study.

\section{CONFLICT OF INTEREST}

The authors declare no conflict of interest, financial or otherwise.

\section{AUTHOR CONTRIBUTIONS}

$\varnothing . S ., \mathrm{JH}, \mathrm{CC}$, and BR conceived and designed the experiment. Ø.S., JH, CC, JALC, and MA collected the data. Ø.S., BR, and MA analyzed the data. Ø.S., JH, CC, and JALC interpreted the data. Ø.S. wrote the first draft. All authors revised and approved the final version of the manuscript.

\section{DATA AVAILABILITY STATEMENT}

The data that support the findings of this study are available on request from the corresponding author. The data are not publicly available due to privacy or ethical restrictions.

\section{ORCID}

Øyvind Skattebo (iD https://orcid.org/0000-0003-0771-9715

Carlo Capelli (D) https://orcid.org/0000-0002-3278-1337

Bjarne Rud (D) https://orcid.org/0000-0001-9692-6542

Jose A. L. Calbet (iD https://orcid.org/0000-0002-9215-6234

Jostein Hallén (D) https://orcid.org/0000-0002-6646-0734

\section{REFERENCES}

1. Saltin B, Calbet JA. Point: in health and in a normoxic environment, VO2 max is limited primarily by cardiac output and locomotor muscle blood flow. J Appl Physiol. 1985;2006(100):744-745.

2. Calbet JA, Rådegran G, Boushel R, Saltin B. On the mechanisms that limit oxygen uptake during exercise in acute and chronic hypoxia: role of muscle mass. J Physiol. 2009;587:477-490.

3. Koskolou MD, Roach RC, Calbet JA, Rådegran G, Saltin B. Cardiovascular responses to dynamic exercise with acute anemia in humans. Am J Physiol. 1997;273:H1787-1793.

4. Calbet JA, Gonzalez-Alonso J, Helge JW, et al. Central and peripheral hemodynamics in exercising humans: leg vs arm exercise. Scand J Med Sci Sports. 2015;25(Suppl 4):144-157.

5. Cardinale DA, Larsen FJ, Jensen-Urstad M, et al. Muscle mass and inspired oxygen influence oxygen extraction at maximal exercise: Role of mitochondrial oxygen affinity. Acta Physiol (Oxf). 2019;225:e13110.

6. Gifford JR, Garten RS, Nelson AD, et al. Symmorphosis and skeletal muscle $\mathrm{VO}_{2 \max }$. In Vivo and in vitro measures reveal differing 
constraints in the exercise-trained and untrained human. $J$ Physiol. 2016;594:1741-1751.

7. Blomstrand E, Rådegran G, Saltin B. Maximum rate of oxygen uptake by human skeletal muscle in relation to maximal activities of enzymes in the Krebs cycle. J Physiol. 1997;501(Pt 2):455-460.

8. Pedersen PK, Kiens B, Saltin B. Hyperoxia does not increase peak muscle oxygen uptake in small muscle group exercise. Acta Physiol Scand. 1999;166:309-318.

9. Mourtzakis M, Gonzalez-Alonso J, Graham TE, Saltin B. Hemodynamics and $\mathrm{O}_{2}$ uptake during maximal knee extensor exercise in untrained and trained human quadriceps muscle: effects of hyperoxia. J Appl Physiol. 1985;2004(97):1796-1802.

10. Esposito F, Reese V, Shabetai R, Wagner PD, Richardson RS. Isolated quadriceps training increases maximal exercise capacity in chronic heart failure: the role of skeletal muscle convective and diffusive oxygen transport. J Am Coll Cardiol. 2011;58:1353-1362.

11. Gonzalez-Alonso J, Olsen DB, Saltin B. Erythrocyte and the regulation of human skeletal muscle blood flow and oxygen delivery: role of circulating ATP. Circ Res. 2002;91:1046-1055.

12. Richardson RS, Grassi B, Gavin TP, et al. Evidence of O2 supply-dependent $\mathrm{VO}_{2}$ max in the exercise-trained human quadriceps. J Appl Physiol. 1985;1999(86):1048-1053.

13. Mortensen SP, Morkeberg J, Thaning P, Hellsten Y, Saltin B. Two weeks of muscle immobilization impairs functional sympatholysis but increases exercise hyperemia and the vasodilatory responsiveness to infused ATP. Am J Physiol Heart Circ Physiol. 2012;302:H2074-2082.

14. Boushel R, Gnaiger E, Calbet JA, et al. Muscle mitochondrial capacity exceeds maximal oxygen delivery in humans. Mitochondrion. 2011;11:303-307.

15. Boushel R, Ara I, Gnaiger E, et al. Low-intensity training increases peak arm VO2 by enhancing both convective and diffusive $\mathrm{O} 2$ delivery. Acta Physiol (Oxf). 2014;211:122-134.

16. Montero D, Diaz-Canestro C, Lundby C. Endurance training and $\mathrm{VO}_{2 \max }$ : role of maximal cardiac output and oxygen extraction. Med Sci Sports Exerc. 2015;47:2024-2033.

17. Rud B, Foss O, Krustrup P, Secher NH, Hallén J. One-legged endurance training: leg blood flow and oxygen extraction during cycling exercise. Acta Physiol (Oxf). 2012;205:177-185.

18. Roca J, Agusti AG, Alonso A, et al. Effects of training on muscle $\mathrm{O}_{2}$ transport at $\mathrm{VO}_{2 \max }$. J Appl Physiol. 1985;1992(73):1067-1076.

19. Skattebo $\varnothing$, Bjerring AW, Auensen M, et al. Blood volume expansion does not explain the increase in peak oxygen uptake induced by 10 weeks of endurance training. Eur J Appl Physiol. 2020;120:985-999.

20. Robinson DM, Ogilvie RW, Tullson PC, Terjung RL. Increased peak oxygen consumption of trained muscle requires increased electron flux capacity. J Appl Physiol. 1985;1994(77):1941-1952.

21. Henriksson J. Training induced adaptation of skeletal muscle and metabolism during submaximal exercise. J Physiol. 1977;270:661-675.

22. Saltin B, Nazar K, Costill DL, et al. The nature of the training response; peripheral and central adaptations of one-legged exercise. Acta Physiol Scand. 1976;96:289-305.

23. Andersen P, Saltin B. Maximal perfusion of skeletal muscle in man. J Physiol. 1985;366:233-249.
24. Rådegran G, Blomstrand E, Saltin B. Peak muscle perfusion and oxygen uptake in humans: importance of precise estimates of muscle mass. J Appl Physiol. 1985;1999(87):2375-2380.

25. Kelman GR. Digital computer subroutine for the conversion of oxygen tension into saturation. J Appl Physiol. 1966;21:1375-1376.

26. Roca J, Hogan MC, Story D, et al. Evidence for tissue diffusion limitation of $\mathrm{VO}_{2 \max }$ in normal humans. J Appl Physiol. 1985;1989(67):291-299.

27. Calbet JA, Holmberg HC, Rosdahl H, van Hall G, Jensen-Urstad M, Saltin B. Why do arms extract less oxygen than legs during exercise? Am J Physiol Regul Integr Comp Physiol. 2005;289:R1448-1458.

28. Calbet JA, Losa-Reyna J, Torres-Peralta R, et al. Limitations to oxygen transport and utilization during sprint exercise in humans: evidence for a functional reserve in muscle $\mathrm{O}_{2}$ diffusing capacity. $J$ Physiol. 2015;593:4649-4664.

29. Piiper J. Perfusion, diffusion and their heterogeneities limiting blood-tissue $\mathrm{O}_{2}$ transfer in muscle. Acta Physiol Scand. 2000;168:603-607.

30. Hallén J, Saltin B, Sejersted OM. K+ balance during exercise and role of beta-adrenergic stimulation. Am J Physiol. 1996;270:R1347-1354.

31. Andersen P, Adams RP, Sjogaard G, Thorboe A, Saltin B. Dynamic knee extension as model for study of isolated exercising muscle in humans. J Appl Physiol. 1985;1985(59):1647-1653.

32. Borg G. Psychophysical scaling with applications in physical work and the perception of exertion. Scand J Work Environ Health. 1990;16(Suppl 1):55-58.

33. Larsen S, Nielsen J, Hansen CN, et al. Biomarkers of mitochondrial content in skeletal muscle of healthy young human subjects. $J$ Physiol. 2012;590:3349-3360.

34. Thomassen M, Hostrup M, Murphy RM, et al. Abundance of ClC-1 chloride channel in human skeletal muscle: fiber type specific differences and effect of training. J Appl Physiol. 1985;2018(125):470-478.

35. Kiens B, Essen-Gustavsson B, Christensen NJ, Saltin B. Skeletal muscle substrate utilization during submaximal exercise in man: effect of endurance training. J Physiol. 1993;469:459-478.

36. Blomstrand E, Krustrup P, Sondergaard H, Rådegran G, Calbet JA, Saltin B. Exercise training induces similar elevations in the activity of oxoglutarate dehydrogenase and peak oxygen uptake in the human quadriceps muscle. Pflugers Arch. 2011;462:257-265.

37. Krustrup P, Hellsten Y, Bangsbo J. Intense interval training enhances human skeletal muscle oxygen uptake in the initial phase of dynamic exercise at high but not at low intensities. $J$ Physiol. 2004;559:335-345.

38. Nyberg M, Egelund J, Mandrup CM, et al. Leg vascular and skeletal muscle mitochondrial adaptations to aerobic high-intensity exercise training are enhanced in the early postmenopausal phase. $J$ Physiol. 2017;595:2969-2983.

39. Klausen K, Secher NH, Clausen JP, Hartling O, Trap-Jensen J. Central and regional circulatory adaptations to one-leg training. $J$ Appl Physiol. 1982;52:976-983.

40. Boushel R, Saltin B. Ex vivo measures of muscle mitochondrial capacity reveal quantitative limits of oxygen delivery by the circulation during exercise. Int J Biochem Cell Biol. 2013;45:68-75.

41. Boushel R, Gnaiger E, Larsen FJ, et al. Maintained peak leg and pulmonary $\mathrm{VO}_{2}$ despite substantial reduction in muscle mitochondrial capacity. Scand J Med Sci Sports. 2015;25:135-143. 
42. Knight DR, Poole DC, Schaffartzik W, et al. Relationship between body and leg $\mathrm{VO}_{2}$ during maximal cycle ergometry. J Appl Physiol. 1985;1992(73):1114-1121.

43. Beere PA, Russell SD, Morey MC, Kitzman DW, Higginbotham MB. Aerobic exercise training can reverse age-related peripheral circulatory changes in healthy older men. Circulation. 1999;100:1085-1094.

44. Hepple RT, Hagen JL, Krause DJ. Oxidative capacity interacts with oxygen delivery to determine maximal $\mathrm{O}(2)$ uptake in rat skeletal muscles in situ. J Physiol. 2002;541:1003-1012.

45. McAllister RM, Terjung RL. Acute inhibition of respiratory capacity of muscle reduces peak oxygen consumption. Am J Physiol. 1990;259:C889-896.

46. Wagner PD. Diffusive resistance to $\mathrm{O}_{2}$ transport in muscle. Acta Physiol Scand. 2000;168:609-614.

47. Skattebo $\varnothing$, Calbet JAL, Rud B, Capelli C \& Hallen J. (2020). Contribution of oxygen extraction fraction to maximal oxygen uptake in healthy young men. Acta Physiol (Oxf). htps://doi. org/10.1111/apha.13486

48. Hoppeler H, Howald H, Conley $\mathrm{K}$, et al. Endurance training in humans: aerobic capacity and structure of skeletal muscle. J Appl Physiol. 1985;1985(59):320-327.

49. Meinild Lundby AK, Jacobs RA, Gehrig S, et al. Exercise training increases skeletal muscle mitochondrial volume density by enlargement of existing mitochondria and not de novo biogenesis. Acta Physiol (Oxf). 2018;222:e12976.

50. Aw TY. Intracellular compartmentation of organelles and gradients of low molecular weight species. Int Rev Cytol. 2000;192:223-253.

51. Hood DA. Invited Review: contractile activity-induced mitochondrial biogenesis in skeletal muscle. J Appl Physiol. 1985;2001(90):1137-1157.

52. Ferretti G, Antonutto G, Denis C, et al. The interplay of central and peripheral factors in limiting maximal $\mathrm{O}_{2}$ consumption in man after prolonged bed rest. J Physiol. 1997;501(Pt 3):677-686.

53. Saltin B, Blomqvist G, Mitchell JH, Johnson RL Jr, Wildenthal K, Chapman CB. Response to exercise after bed rest and after training. Circulation. 1968;38:VII1-78.

54. Wagner PD. Central and peripheral aspects of oxygen transport and adaptations with exercise. Sports Med. 1991;11:133-142.
55. di Prampero PE, Ferretti G. Factors limiting maximal oxygen consumption in humans. Respir Physiol. 1990;80:113-127.

56. Ekblom B, Goldbarg AN, Kilbom A, Astrand PO. Effects of atropine and propranolol on the oxygen transport system during exercise in man. Scand J Clin Lab Invest. 1972;30:35-42.

57. Pawelczyk JA, Hanel B, Pawelczyk RA, Warberg J, Secher NH. Leg vasoconstriction during dynamic exercise with reduced cardiac output. J Appl Physiol. 1985;1992(73):1838-1846.

58. Stringer W, Wasserman K, Casaburi R, Porszasz J, Maehara K, French W. Lactic acidosis as a facilitator of oxyhemoglobin dissociation during exercise. J Appl Physiol. 1985;1994(76):1462-1467.

59. Richardson RS, Tagore K, Haseler LJ, Jordan M, Wagner PD. Increased $\mathrm{VO}_{2}$ max with right-shifted $\mathrm{Hb}-\mathrm{O}_{2}$ dissociation curve at a constant $\mathrm{O}_{2}$ delivery in dog muscle in situ. $J$ Appl Physiol. 1985;1998(84):995-1002.

60. Hellsten Y, Nyberg M, Jensen LG, Mortensen SP. Vasodilator interactions in skeletal muscle blood flow regulation. J Physiol. 2012;590:6297-6305.

61. Rozier MD, Zata VJ, Ellsworth ML. Lactate interferes with ATP release from red blood cells. Am J Physiol Heart Circ Physiol. 2007;292:H3038-3042.

62. Ellsworth ML. Red blood cell-derived ATP as a regulator of skeletal muscle perfusion. Med Sci Sports Exerc. 2004;36:35-41.

63. Mortensen SP, Nyberg M, Gliemann L, Thaning P, Saltin B, Hellsten Y. Exercise training modulates functional sympatholysis and alpha-adrenergic vasoconstrictor responsiveness in hypertensive and normotensive individuals. J Physiol. 2014;592:3063-3073.

How to cite this article: Skattebo Ø, Capelli C, Rud B, Auensen M, Calbet JAL, Hallén J. Increased oxygen extraction and mitochondrial protein expression after small muscle mass endurance training. Scand J Med Sci Sports. 2020;30:1615-1631. https://doi.org/10.1111/ $\underline{\text { sms. } 13707}$ 